University of South Florida

DIGITAL COMMONS

Digital Commons @ University of

@ UNIVERSITY OF SOUTH FLORIDA

South Florida

$3-24-2008$

\title{
Investigating the Role of Appearance-Based Factors in Predicting Sunbathing and Tanning Salon Use
}

\author{
Guy Cafri \\ University of South Florida
}

Follow this and additional works at: https://digitalcommons.usf.edu/etd

Part of the American Studies Commons

\section{Scholar Commons Citation}

Cafri, Guy, "Investigating the Role of Appearance-Based Factors in Predicting Sunbathing and Tanning Salon Use" (2008). USF Tampa Graduate Theses and Dissertations.

https://digitalcommons.usf.edu/etd/156

This Dissertation is brought to you for free and open access by the USF Graduate Theses and Dissertations at Digital Commons @ University of South Florida. It has been accepted for inclusion in USF Tampa Graduate Theses and Dissertations by an authorized administrator of Digital Commons @ University of South Florida. For more information, please contact digitalcommons@usf.edu. 
Investigating the Role of Appearance-Based Factors in Predicting Sunbathing and Tanning Salon Use

by

\title{
Guy Cafri
}
A dissertation submitted in partial fulfillment of the requirements for the degree of Doctor of Philosophy Department of Psychology College of Arts and Sciences University of South Florida

\author{
Major Professor: Joel Kevin Thompson, Ph.D. \\ Paul Jacobsen, Ph.D. \\ Thomas Brandon, Ph.D. \\ William Sacco, Ph.D. \\ Michael Brannick, Ph.D. \\ Rita Debate, Ph.D. \\ Date of Approval: \\ March 24, 2008
}

Keywords: Skin cancer, sunbathing, indoor tanning, body image, theory of planned behavior

(C) Copyright 2008, Guy Cafri 


\section{Table of Contents}

List of Tables $\quad$ ii

List of Figures $\quad$ iii

Abstract $\quad$ iv

$\begin{array}{ll}\text { Introduction } & 1\end{array}$

Method $\quad 4$

Participants 4

Procedure $\quad 4$

Measures $\quad 4$

Appearance Factors 4

Perceived Threat-Skin Cancer $\quad 5$

Skin Cancer Risk

UV Exposure Behaviors $\quad 5$

UV Exposure Intentions

Missing Data $\quad 6$

$\begin{array}{ll}\text { Results } & 7\end{array}$

$\begin{array}{ll}\text { Attrition } & 7\end{array}$

$\begin{array}{ll}\text { Outliers and Normality } & 7\end{array}$

Model Comparisons $\quad 8$

$\begin{array}{ll}\text { Interpretation of the Final Model } & 9\end{array}$

$\begin{array}{ll}\text { Discussion } & 10\end{array}$

Implications on Theory $\quad 10$

Implications for the Design of Interventions 11

$\begin{array}{ll}\text { Footnotes } & 13\end{array}$

$\begin{array}{ll}\text { References } & 15\end{array}$

$\begin{array}{ll}\text { Appendices } & 20\end{array}$

Appendix A: Scale Items $\quad 21$

Appendix B: Tables and Figures $\quad 24$

About the Author $\quad$ End Page 


\section{List of Tables}

Table 1

Table 2

Table 3

Table 4

Table 5

Table 6

Table 7

Table 8
Means, Standard Deviations, and Reliability of Scales

Correlations Among Scales

Tests of Alternative Models (without item deletion)

Tests of Alternative Models (with item deletion)

Tests of Alternative Models (outliers deleted)

Tests of Indirect Effects (without item deletion)

Tests of Indirect Effects (with item deletion)

Tests of Indirect Effects (with outliers deleted)
24

27

28

29

30

31

32

33 


\section{List of Figures}

Figure 1

Figure 2

Figure 3

Figure 4

Figure 5

Figure 6

Figure 7.

Figure 8.
Hypothesized Model

Alternative Models for the Role of Intentions/Behaviors

35

Alternative Model for the Role of Sociocultural Influence 36

Alternative Models for the Role of Perceived Threat

37

Alternative Model for the Role of Skin Cancer Risk

38

Standardized Path Coefficients (without item deletion)

39

Standardized Path Coefficients (with item deletion)

40

Standardized Path Coefficients (with outlier deletion) 
Investigating the Role of Appearance-Based Factors in Predicting Sunbathing and

\author{
Tanning Salon Use
}

Guy Cafri

\begin{abstract}
Understanding the motives for sunbathing and indoor tanning is an extremely important public health issue. UV exposure via sunbathing and utilization of sun lamps and tanning beds are considered important risk factors for the development of skin cancer. Psychosocial models of UV exposure are often based on theories of health behavior, but theory from the body image field can be useful in understanding motives to UV expose as well. The current study examines models that prospectively predict sunbathing and indoor tanning behaviors using constructs and interrelationships derived from the tripartite theory of body image (Thompson et al., 1999), as well as those from the theory of reasoned action (Ajzen \& Fishbein, 1980), health belief model (Rosenstock, 1974), revised protection motivation theory (Rogers, 1983), and a proposed integration of several health behavior models (Fishbein, 2000). The results generally support a model in which intentions mediate the relationship between appearance attitudes and tanning behaviors, appearance reasons to tan and intentions mediate the relationship between sociocultural influences and tanning behaviors, and appearance reasons not to tan and intentions mediate the role of perceived threat on behaviors. The implications of these findings yield important information relevant to the understanding of motives to UV expose, which can useful to the development of novel prevention and early intervention programs geared toward the reduction of skin cancer risk.
\end{abstract}


Introduction

The incidence of skin cancers has reached epidemic proportions in the United States with more than 1 million cases of basal and squamous cell carcinoma and 59,940 cases of malignant melanoma expected to be diagnosed in 2007 (8,110 deaths projected from melanoma; American Cancer Society, 2007). Research suggests that ultraviolet (UV) radiation through sun and sunbed/sunlamp exposure is a central risk factor for the development of skin cancers (e.g., U.S. Department of Health and Human Services, 2002). In the aims of reducing skin cancer risk, researchers have attempted to better understand motives for UV exposure. The framework for understanding sunbathing and indoor tanning salon use has been primarily influenced by theories of health behavior (e.g., theory of planned behavior; Ajzen, 1985; for an application see: Hillhouse, Adler, Drinnon, \& Turrisi, 1997). Although empirical models based on these theories have been informative, incorporating constructs and hypothesized relationships based on theory from the body image field can be useful in understanding motives to UV expose because UV exposure is consistently related to wanting to look tan (e.g., Hillhouse, Turrisi, \& Kastner, 2000; Wichstrom, 1994), and appearance-focused interventions have been found to be efficacious (Gibbons et al., 2005; Hillhouse \& Turrisi, 2002; Jackson \& Aiken, 2006; Jones \& Leary, 1994; Mahler et al., 2003; Mahler et al., 2005). Preliminary application of one body image theory, the tripartite theory (Thompson Heinberg, Altabe, \& Tantleff-Dunn, 1999), to the area of tanning behavior has identified constructs (Cafri, Thompson, Roehrig et al., 2006; Cafri et al., in press) and relationships among constructs (Cafri, Thompson, \& Jacobsen, 2006) that have further elucidated the reasons for UV exposure.

The goal of the current paper is to examine the extent to which biopsychosocial factors predict sunbathing and indoor tanning behaviors prospectively (at six month follow-up), using constructs primarily derived from the body image field, but selected constructs from theories of health behavior as well. Relationships hypothesized by the theory of reasoned action (Ajzen \& Fishbein, 1980), health belief model (Rosenstock, 1974), revised protection motivation theory (Rogers, 1983), a proposed integration of several health behavior models (Fishbein, 2000), and the tripartite theory of body image (Thompson et al., 1999) are considered, and aspects of these theories are tested using structural equation modeling.

The theory of reasoned action (Ajzen \& Fishbein, 1980) is a social psychology theory used for the study of many health behaviors. The theory posits that attitudes toward a behavior and subjective norms predict intentions to behave, which in turn predict the particular behavior. The theory of planned behavior (Ajzen, 1985) adapts this theory to include behavioral control. The application of the theories of reasoned action and planned behavior to the study of UV exposure indicates that intentions to sunbathe and indoor tan are positively associated with their respective behaviors (Hillhouse et al., 1997; Jackson \& Aiken, 2000). Moreover, attitudes, subjective norms, and perceived 
behavioral control were found to be positively associated with sunbathing and indoor tanning intentions (Hillhouse et al., 1997; Hillhouse et al., 2000; Jackson \& Aiken 2000). One important limitation of past research is that models examining the association between intentions and their predictors are fit without including the corresponding behavior, or if the behavior is included, its association with intentions is evaluated separately from predictors of intentions (e.g., Jackson \& Aiken, 2000; Hillhouse et al., 1997). This strategy generally precludes a comprehensive test of the theory of planned behavior as applied to UV exposure, and specifically limits evaluation of the indirect effects of attitudes/subjective norms on the behavior of interest. A final limitation to consider is in many research studies either sunbathing or tanning salon use is assessed (e.g., Jackson \& Aiken, 2000), however, both should be evaluated because both are risk factors for the development of skin cancer (U.S. Department of Health and Human Services, 2002).

The health belief model (Rosenstock, 1974) proposes that individuals adopt a protective behavior to the extent that they perceive themselves to be susceptible, perceive the outcome to be severe, benefits of the behavior are protective against the threat, and barriers to the protective behavior can be overcome. Revised protection motivation theory (Rogers, 1983) builds upon the health belief model by arguing that perceived threat (perceived susceptibility + perceived severity) elicits a fear response that reduces the probability of maladaptive responses (e.g., UV exposure), suggesting a direct effect on intentions/behaviors. In contrast, Fishbein (2000) has argued that perceived threat only has an indirect influence on intentions/behaviors, mediated through major constructs of the theory of planned behavior (norms, attitudes, behavioral control). If perceived susceptibility is viewed as a proxy for perceived threat, one study found support for both revised protection motivation theory and Fishbein's (2000) view, such that susceptibility was associated with intentions to sunbathe and advantages of sunbathing mediated the relationship between these two variables (Jackson \& Aiken, 2000). In the same study, the authors hypothesized and found evidence that perceived susceptibility mediates the relationship between skin cancer risk (based on skin type and family history of skin cancer) and intentions to sunbathe. Skin cancer risk based on physical indicators (e.g., skin type) is often considered a substantive demographic characteristic or a confounding variable in models of UV exposure, therefore its direct relationship to outcome variables is typically considered. However, Jackson and Aiken (2000) found no evidence for the direct relationship on intentions beyond the indirect effect discussed above.

The tripartite theory of body image (Thompson et al., 1999) posits that appearance-based sociocultural influences (peers, parents, media) lead to body dissatisfaction, which in turn lead to eating disorder symptoms. Several studies have already identified a significant relationship between appearance motives and intentions/behaviors to UV expose (Hillhouse, Stair, \& Adler, 1996; Hillhouse et al., 1997; Hillhouse, et al., 2000; Jackson \& Aiken, 2000; Wichstrom, 1994). However, the manner in which appearance is assessed is not always specific to tanning, scales can be confounded with indicators that are not appearance-based, and the scales have limited evidence of construct validity. Consistent with the tripartite theory, two studies recently demonstrated the multidimensional nature of appearance motives (Cafri, Thompson, Roehrig et al., 2006; Cafri et al., in press), such that there are three higher-order factors: 
sociocultural influences to tan, appearance reasons to tan, and appearance reasons not to tan. Also consistent with the tripartite theory, a series of mediation models demonstrated that general attractiveness reasons for tanning mediated the relationship between media influence and intentions/behaviors to UV expose (Cafri, Thompson, \& Jacobsen, 2006). A more comprehensive model, including all facets of the abovementioned higher-order constructs, as well as other relevant variables, has not been tested.

A model illustrating hypothesized relationships based on the aforementioned theories can be found in Figure 1. Based on the theory of reasoned action, it is hypothesized that intentions will mediate the relationship between each of the following and UV exposure behaviors (evaluated at six month follow-up): appearance reasons to tan, appearance reasons not to tan, and perceived threat. Based on the tripartite theory, appearance reasons to tan are predicted to have a positive relationship with intentions to sunbathe, appearance reasons not to tan will have a negative relationship, and appearance reasons to tan will mediate the relationship between sociocultural influence and intentions. Based on an extension of the health belief model (Jackson \& Aiken, 2000) and revised protection motivation theory, perceived threat is predicted to mediate the relationship between skin cancer risk and intentions to tan, such that risk will be positively associated with threat and threat will be negatively associated with intentions to tan. Based on Fishbein's (2000) integrative model and the empirical results of Jackson and Aiken (2000), an inverse relationship between perceived threat and appearance reasons to tan, and a positive relationship between perceived threat and appearance reasons not to tan are expected.

Theory from the areas of body image and health psychology offer a useful framework for hypothesizing relationships among variables that can be used to predict UV exposure behaviors. A series of competing hypotheses about the relationships among the variables can be constructed based on these theories. Hypotheses will be tested using structural equation models. The model that is most consistent with the data will be interpreted in terms of the magnitude and statistical significance of the path coefficients. 


\section{Participants}

\section{Method}

The primary sample consists of 589 females from the University of South Florida that were reported on in a previous study (Cafri et al., in press). We chose to focus on females because as a group they are more likely than males to use indoor tanning salons and engage in outdoor tanning behaviors (Davis, Cokkinides, Weinstock, O’Connell, \& Wingo, 2002; Demko, Borawski, Debanne, Cooper, \& Stange, 2003; Lazovich et al., 2004), and thus are at greater risk for developing skin cancer. Furthermore, the rates of tanning behavior, in particular tanning salon use, were extremely low for a sample of university males (Cafri et al., in press). Additional criteria included being between 18 and $26(\mathrm{M}=19.88, \mathrm{SD}=1.84)$ in order for the sample to be representative of young adults, as well as having a skin type between I and IV (Fitzpatrick, 1988) because individuals with skin types V and VI (i.e., brown or black skin color) are at a significantly reduced risk for developing skin cancer (Goldsmith, 1987). The racial distribution of participants was 80\% White/Caucasian, 5 \% Black/African American, 3\% Asian/Pacific Islander, >1\% American Indian/ Alaska Native, and 11\% Other. Percentages of participant skin types were: $12 \%$ Type I, 26\% Type II, 36\% Type III, and 26\% Type IV. In order to measure the temporal stability of the measures, an independent sample of 80 females resembling the primary sample in demographic characteristics, was evaluated during the months of April and May by measuring same individuals twice over the course of one week. Procedure

Participants were recruited from introductory psychology classes. Questionnaires were completed online. Time 1 data on biopsychosocial variables and intentions to UV expose were collected between the months of October and November. Time 2 data on UV exposure behaviors were collected six months later between the months of April and May. In order to minimize attrition, participants were contacted a minimum of five times by email and phone before they were considered non-responders. A total of 311 participants (52\%) completed the survey at Time 2. Participants were given course credit for their participation at Time 1 and given the option of course credit or \$15 at Time 2. Measures

Appearance Factors. Three appearance factors developed in previous studies (Cafri, Thompson, Roehrig et al., 2006; Cafri et al., in press) are used in the current study (see Figure 1): sociocultural influences to tan, appearance reasons to tan, and appearance reasons not to tan. In the current study, each of these three factors is specified as a higherorder factor, with lower-order factor indicators, with each of these lower-order factors in turn having individual items serving as indicators (for exact specifications of the measurement model see: Cafri et al., in press). Each item is measured on a 5-point Likert scale. The sociocultural influences to tan factor consists of four lower-order factors: media, friends, family, and significant others. Appearance reasons to tan factor includes three lower-order factors: general appearance enhancement, reducing the appearance of 
acne, and enhancement of body shape. Appearance reasons not to tan consists of two lower-order factors: skin aging and immediate skin damage. Evidence for validity of the scales includes: item construction based on previous theory/research in the body image field and focus groups with people who tan, exploratory and confirmatory factor analytic models, and convergence of factors with UV exposure and protection outcomes (Cafri, Thompson, Roehrig et al., 2006; Cafri et al., in press). ${ }^{1}$

Perceived Threat-Skin Cancer. Perceived threat is specified as a higher-order factor, with perceived susceptibility and perceived severity as lower-order factor indicators, with each of these lower-order factors in turn having individual items serving as indicators. Perceived susceptibility is measured using a four item measure, each item with a 6-point Likert response format (Jackson \& Aiken, 2000). Based on the results of a previous study there is evidence of validity based on confirmatory factor analysis, as well as reliability (test-retest $r=.72$; Coefficient $\alpha=.63$, .71; Jackson and Aiken, 2000). Perceived severity is measured using a three item measure, each item with a 6-point Likert response format (Jackson \& Aiken, 2000). Based on the results of a previous study there is evidence of validity based on confirmatory factor analysis, as well as internal consistency reliability, but not test-retest reliability (test-retest $r=.46$; Coefficient $\alpha=$ .64, .77; Jackson and Aiken, 2000). Notably, test-retest reliability estimates are higher in the current sample (see Table 1).

Skin Cancer Risk. Risk for skin cancer was assessed using two items, skin type (6point Likert scale; Fitzpatrick, 1988) and untanned skin color (3-point Likert scale; Weinstock, 1992). These items had a statistically significant association with sunsensitivity in a previous study, as measured by minimal erythema dose, the dose of ultraviolet B light required to produce visible redness of the skin (Weinstock, 1992). Sun sensitivity is a major risk factor for melanoma, therefore these findings reflect criterionrelated validity. Temporal stability of the skin type measure was adequate in a previous study (test-retest $r=.82$; Jackson \& Aiken, 2000).

UV Exposure Behaviors at Six Month Follow-Up. Indoor tanning was assessed with a single item that asks about use over the past six months ("Please give me your best estimate of how many times you have indoor tanned in the last 6 months; Hillhouse, Turrisi, Holwiski \& McVeigh, 1999). Participants respond to the item by checking the box that best approximates the range of times they indoor tan on a seven-point scale $(0$, $1-10,11-20,21-30$, etc.). Sunbathing behavior was assessed using a single item modeled after the indoor tanning item ("Please give me your best estimate of how many times you have sunbathed in the last 6 months") with an identical scoring method. Test-retest reliability of these items over a 7-10 day period was adequate in a previous sample (indoor $r=.84$, sunbathing $r=.78$; Cafri, Thompson, \& Jacobsen, 2006).

UV Exposure Intentions. Indoor tanning intentions were assed with a single item that asks participants to provide a six month estimate of times they plan to go indoor tanning ("Please give me your best estimate of how many times you plan to use an indoor tanning salon in the next 6 months"; Hillhouse \& Turrisi, 2002). The scoring method is identical to the UV exposure behavior items. Sunbathing intentions were assessed using an item similar to the indoor tanning item ("Please give me your best estimate of how many times you plan to sunbathe in the next 6 months") with an identical scoring format. 
Test-retest reliability of these items over a 7-10 day period was adequate in a previous sample (indoor $r=.88$, sunbathing $r=.82$; Cafri, Thompson, \& Jacobsen, 2006). Missing Data

Three hundred and eleven participants had complete data. Among the 278 participants that did not have complete data (i.e., could not be followed-up at Time 2), information on all measured variables except UV exposure behaviors was available. Missing data for these individuals was handled through maximum likelihood estimation of the raw data (i.e., full information maximum likelihood; Aurbuckle, 1996, Muthen, Kaplan, \& Hollis, 1987). In order for this method to have favorable statistical properties

it at least requires the untestable assumption that the data are missing at random (MAR) ${ }^{2}$ and multivariate normality, but it has been suggested that maximum likelihood is somewhat robust to violations of this latter assumption (Allison, 2001).

\section{Planned Analyses}

Study hypotheses are evaluated using structural equation modeling with maximum likelihood estimates of parameters (AMOS 6.0; Arbuckle, 2005). Specification of the "structural" portion of the models evaluated in this study is detailed throughout, but the "measurement" portion is not. Generally, the measurement portion consists of individual items serving as indicators of their respective factors because this leads to parameter estimation using optimal weights (cf. scale composites using unit weights for items; Bollen \& Lennox, 1991). When only one item is used as an indicator of a latent variable (i.e., UV exposure variables), a value for the error variance is specified by multiplying the variance of the variable in the current sample by its estimate of unreliability. ${ }^{4}$ When testing competing hypotheses about the relationships among the variables, nested models are compared using the likelihood ratio test (i.e., $\Delta \chi^{2}$; difference between chi-square values), and non-nested models are compared using the Akaike information criteria (AIC) and the Browne-Cudek criteria (BCC; Browne \& Cudek, 1989). AIC and BCC are indexes based on the extent to which the model fit the data and also incorporate a penalty for model complexity (they are also interpreted as cross-validation coefficients). When the aim is to evaluate a final model for fit, the point estimate of the Root Mean Square Error of Approximation (RMSEA) and a 90\% confidence interval, Comparative Fit Index (CFI), and the Non-Normed Fit Index (NNFI) are used because of their relatively good performance in simulation studies (e.g., Hu \& Bentler, 1998). Several cut-off values are used to judge model-data fit: RMSEA $<0.05$ suggest good fit, 0.05-0.08 suggest marginal fit, and $>0.10$ suggest questionable fit, and a CFI > .95 indicates good fit (Hu \& Bentler, 1998, 1999; MacCallum, Browne \& Sugawara, 1996). Mediation/indirect effects are based on the product of regression coefficients, with standard errors calculated based on the first-order delta method formula (Sobel, 1982) when there is one mediator, and the multivariate delta method (Taylor, Mackinnon, \& Tein, in press) when there are two mediators. 


\section{Attrition}

Results

It is often of interest to compare participants that dropout with those that were retained in order to determine the extent to which the retained participants are representativeness of the full sample. Based on the results in Table 1 there is an indication that the groups differ on several variables, and on at least one of the variables, general appearance, even after a strict correction of the nominal alpha based on multiple comparisons (Bonferroni adjustment of the nominal alpha level =.003). This also suggests that the data may not be missing completely at random (MCAR) ${ }^{2}$ with respect to the means. More general tests of the MCAR assumption have been suggested (Kim \& Bentler, 2002; Little, 1988; Muthen et al., 1987). ${ }^{3}$ Given the simple pattern of missing data, a multi-group structural equation model was in used, in which unstructured variances, covariances, and means of all measured variables (excluding UV exposure behaviors) are constrained equal across completers and non-completers, $\chi^{2}(1595)=$ 2232.58, $p<.05$, CFI $=.97$, NNFI=.95, RMSEA=.026 (.023, .029). The result suggests that the constraint were reasonable, indicating the two groups come from a single population (Kim \& Bentler, 2002), and in turn that the MCAR assumption cannot be rejected (but may still be false). However, whether or not the MCAR assumption holds is somewhat immaterial because the approach taken to handling the missing data presumes the less stricter assumption that the data are missing at random (MAR). Assuming the data are MAR, parameter estimates will be consistent, asymptotically efficient, and asymptotically normal (Allison, 2001, 2003; Muthen et al., 1987).

\section{Outliers and Normality}

Initially, the data were screened for outliers. Five outliers were identified, and analyses with and without these cases indicated no substantive differences (cf. Tables 3 vs. 5, Tables 6 vs. 8, Figures 6 vs. 8). Mardia's index of multivariate kurtosis was 306.86, and the critical ratio was 34.62 for the model tested, suggesting the presence of multivariate non-normality. ${ }^{5}$ Examination of univariate skewness (SK) and kurtosis (KU) for the individual items associated with all factors except UV exposure variables indicated slight deviations from normality: SK-range .03-1.29, $\mathrm{M}=.51$, SD = .31; KUrange .01-1.37, $\mathrm{M}=.84, \mathrm{SD}=.34$. Univariate indexes suggested more moderate deviations from normality for sunbathing intentions, $\mathrm{SK}=1.24, \mathrm{KU}=1.47$, sunbathing behaviors, $\mathrm{SK}=1.34, \mathrm{KU}=2.48$, tanning intentions, $\mathrm{SK} 1.73, \mathrm{KU}=2.73$, and indoor tanning behaviors, $\mathrm{SK}=1.97, \mathrm{KU}=3.42$. Given concerns related to normality, the UV exposure variables were transformed using a natural log transformation, which resulted in more normal distributions (all SK $<1.31$ and $\mathrm{KU}<.69$ ). Based on simulations studies (West, Finch, \& Curran, 1995; Curran, West, \& Finch, 1996), the impact of nonnormality on the $X^{2}$ statistic, fit indexes, and estimation of standard errors was deemed to be little. The means, standard deviations, internal consistency, and temporal stability estimates of the scales are reported in Table 1. Correlations among unit weighted scale 
scores are provided in Table 2. A measurement model was estimated with all possible correlations among the factors presented in Figure 1. The results suggest adequate fit (see Table 4), as well as provide an upper bound of fit for the subsequent models evaluated. Model Comparisons

A central tenet of the theory of reasoned action adopted in the hypothesized model is that intentions mediate the relationship between appearance attitudes/sociocultural influence and UV exposure behaviors. Alternatively, it might be posited that there is no mediating effect, and instead only a direct influence on behaviors (see Figure 2). A saturated model in which both sets of paths are present (Table 4; Model 1a) was compared to a more constrained model in which intentions mediate the relationship between appearance attitudes/sociocultural influence and UV exposure behaviors (Model 1b). The non-significant difference suggests that the constraints were reasonable. In contrast, there was a significant difference between the saturated model (Model 1a) and two alternatives (Models 1c and 1d), in which the mediating role of intentions between appearance attitudes/sociocultural influence and intentions is ignored, suggesting that the constraints were not reasonable. Another indication that treating intentions as mediators was more appropriate than modeling the direct influence on behaviors is suggested by AIC and BCC values that are substantially lower for model 1b versus either model $1 \mathrm{c}$ or $1 \mathrm{~d}$.

The tripartite theory posits that appearance reasons to tan will mediate the relationship between sociocultural influence and intentions. The alternative model considered here is based on the theory of reasoned action. If sociocultural influences are viewed as subjective norms and appearance reasons to tan and not tan are regarded as attitudes toward the behavior, the theory of reasoned action would predict the same direct relationships with intentions to UV expose as the tripartite theory, but instead of sociocultural influences having an indirect effect, it would be predicted to have a direct effect (see Figure 3). A saturated model in which both sets of paths are present (Table 4; Model 2a) was compared to a model that constrained the direct influence of sociocultural influence on intentions to zero (Model 2b), with the non-significant difference suggesting that the constraints were reasonable. In contrast, there was a significant difference between the saturated model (Model 2a) and an alternative (Models 2c) that constrains to zero the direct influence of sociocultural influence on appearance reasons to tan, suggesting that the constraints were not reasonable. Another indication of the appropriateness of only modeling the indirect influence of sociocultural influence on intentions to tan is suggested by AIC and BCC values that are substantially lower for model $2 \mathrm{~b}$ than model 2c.

A direct relationship between perceived threat and UV intentions is hypothesized based on revised protection motivation theory (Rogers, 1983), as well as an indirect effect through appearance reasons to tan and appearance reasons not to tan, based on the model proposed by Fishbein (2000) and the results of a previous study (Jackson \& Aiken, 2000) (see Figure 4). The hypothesized model is a saturated model in which both sets of paths are present (Table 4; Model 3a), which was compared to a model that constrained the direct influence of perceived threat on appearance reasons to tan and not tan to zero (Model 3b), with a significant difference indicating that the constraints were not appropriate. The non-significant difference between the saturated model (Model 3a) and 
the alternative (Models 3c) that constrains the direct influence of perceived threat on intentions to zero, suggests that the constraints were appropriate. Lower AIC and BCC values for model $3 \mathrm{c}$ than model $3 \mathrm{~b}$ is another indication that modeling only the indirect influence of perceived threat on intentions to tan is appropriate.

Based on an extension of the health belief model (Jackson \& Aiken, 2000), perceived susceptibility is hypothesized to mediate the relationship between skin cancer risk and intentions to sunbathe. Alternatively, there may only be a direct influence of skin cancer risk on intentions to tan (see Figure 5). Whether skin cancer risk has a direct or indirect influence, or both, will be tested by comparing a saturated model in which both sets of paths are present to more constrained models in which only one set of paths is present. A saturated model in which both sets of paths are present (Table 4; Model 4a) was compared to a model that constrained the direct influence of skin cancer risk on intentions to zero (Model 4b), with the non-significant difference suggesting that the constraints were reasonable. In contrast, there was a significant difference between the saturated model (Model 4a) and an alternative (Models 4c) that constrains to zero the direct influence of skin cancer risk on perceived threat, suggesting that the constraints were not reasonable. Another indication of the appropriateness of only modeling the indirect influence of skin cancer risk on intentions to tan is suggested by AIC and BCC values that are substantially lower for model $4 \mathrm{~b}$ than model 4c.

Interpretation of the Final Model

The final model selected was 4b. Standardized regression coefficients and significance tests of individual paths are presented in Figure 7, with only one path not statistically significant. With the exceptions of direct influences of perceived threat on intentions (ruled out based on tests of alternative models) and the non-significant association between perceived threat and appearance reasons to tan, the relationships are generally consistent with what was originally hypothesized (Figure 1). In this model, the $R^{2}$ for sunbathing intentions is .21 and .55 for behaviors, while for indoor tanning intentions it is .24 and .46 for behaviors. Specific indirect effects in the model are also estimated and tested for significance based on this model (Table 7). The results of these analyses suggest support for the mediating pathways posited by the tripartite theory of body image and theory of reasoned action (entries 1, 4, 5, 6, 9, and 10), and partial support for mediating mechanisms posited by Fishbein's (2000) integrative model (i.e., entries 3 and 8 , but not 2 and 7). ${ }^{6}$ 


\section{Discussion}

This study examined models that prospectively predict sunbathing and indoor tanning behaviors using constructs and hypothesized relationships derived from theories of body image and health behavior. The results generally support a model in which intentions mediate the relationship between appearance attitudes and tanning behaviors, appearance reasons to tan and intentions mediate the relationship between sociocultural influences and tanning behaviors, and appearance reasons not to tan and intentions mediate the role of perceived threat on behaviors. The implications of these findings on research designed to identify risk variables and interventions are considered below. Implications on Theory

The results suggest that intentions mediate the relationship between appearance attitudes and tanning behaviors, which is consistent with the theory of reasoned action (Ajzen \& Fishbein, 1980). Although previous studies have identified a significant univariate association between intentions and behaviors (e.g., Jackson \& Aiken, 2000; Hillhouse et al., 1997), such analyses are unable to rule out alternative models in which attitudes have a direct influence on behaviors, precluding a more rigorous test of the theory of reasoned action undertaken in this study. Moreover, the simultaneous modeling of intentions and behaviors enables estimates and tests of the indirect effects of attitudes and social norms on UV exposure behaviors.

A relatively strong direct relationship between appearance reasons to tan and intentions was observed, as well as an indirect effect with behaviors to UV expose. This result is consistent with past research (Cafri, Thompson, Roehrig et al., 2006; Hillhouse et al., 1996; Hillhouse et al., 1997; Hillhouse, et al., 2000; Jackson \& Aiken, 2000; Wichstrom, 1994), but as noted above, estimation of the indirect effect of appearance reasons to tan on UV exposure behaviors (via intentions) represents a unique contribution to the existing literature. Moreover, appearance reasons to tan and intentions were found to mediate the relationship between sociocultural influences and tanning behaviors, which is consistent with the tripartite theory of body image (Thompson et al., 1999). This outcome is also in line with the results of a previous study (Cafri, Thompson, \& Jacobsen, 2006), but use of a more comprehensive model, indicates a result with greater validity.

A modest direct relationship between appearance reasons not to tan and intentions was observed, as well as an indirect effect with behaviors. The direct relationship with intentions is consistent with the results of the only other study to examine appearance reasons not to tan (Cafri, Thompson, Roehrig et al., 2006), and estimation of the indirect effect of appearance reasons not to tan on UV exposure behaviors (via intentions) is a novel result. Furthermore, appearance reasons not to tan and intentions were found to mediate the role of perceived threat on behaviors. This is only partially supports the application of Fishbein's (2000) model in this context, because the appearance reasons to tan factor was not found to be a mediator. 


\section{Implications for the Design of Interventions}

One of the major implications of the results on the design of interventions is that components should be designed to target appearance reasons to tan and sociocultural influences because existing appearance-based interventions target only appearance reasons not to tan (Gibbons et al., 2005; Hillhouse \& Turrisi, 2002; Jackson \& Aiken, 2006; Jones \& Leary, 1994; Mahler et al., 2003; Mahler et al., 2005). For instance, reduction of the positive valuation of a tan appearance could be achieved through a cognitive dissonance approach in which people who tan are asked to challenge their idealization of a tan appearance. An indication of the prospective utility of such an approach in decreasing UV exposure behaviors is that dissonance interventions have been found in several controlled investigations to reduce body dissatisfaction and eating disturbances in samples at-risk for developing an eating disorder (e.g., Stice, Trost, \& Chase, 2003). Notably, one multi-component intervention has manipulated perceived media influence through emphasizing a growing trend toward untanned skin tone in the media, with evidence of program efficacy (Jackson \& Aiken, 2006). Certainly, other sociocultural influences, such as peer norms for a tan appearance, should also be considered as targets in future interventions. In light of the substantial direct effect sociocultural influences have on appearance reasons to tan and indirect effects on behaviors to UV expose, and considering the significant role childhood/ adolescence play in attitude formation, attempting to change perceived sociocultural norms at a young age as part of an early intervention program could substantially reduce UV exposure behaviors later on in life.

A slightly different approach to the design of interventions than the one considered above, is to focus on behavioral alternatives to UV expose (Turrisi, Hillhouse \& Gebert, 1998), such as the use of sunless tanning products. One study distributed sunless tanning samplers as an adjunct to an existing intervention, but found no significant differences with an intervention alone condition, although these significance tests were characterized by low statistical power (Mahler et al., 2005). Moreover, caution should be exercised because the use of sunless tanning products may perpetuate an appearance norm that in the long run leads to more UV exposure.

The observed associations between appearance reasons not to tan and intentions/behaviors to UV expose are consistent with the efficacy of interventions that target this construct (Gibbons et al., 2005; Hillhouse \& Turrisi, 2002; Jackson \& Aiken, 2006; Jones \& Leary, 1994; Mahler et al., 2003; Mahler et al., 2005). Moreover, given the moderate indirect effect of perceived threat on tanning behaviors, existing and future interventions should consider coupling a component that manipulates perceived threat (i.e., susceptibility and severity) with appearance reasons not to tan. At least one intervention has done this, with evidence of program efficacy (Jackson \& Aiken, 2006). Consistent with earlier arguments regarding the targeting of perceived sociocultural influences as part of an early intervention program, emphasizing the threat of skin cancer at a young age may lead to growth in appearance reasons not to tan, which in turn might reduce UV exposure behaviors later on in life.

Several limitations of this study should be considered. First, with respect to external validity, the exclusive use of female college students who are predominantly Caucasian limits the extent to which these findings can be generalized. It is however 
important to recognize that adolescent and young adult Caucasian females represent a very high-risk group, both in terms of skin-type susceptibility and use of behaviors that lead to skin cancer (Davis et al., 2002; Demko et al., 2003; Lazovich et al., 2004). Nevertheless, it would be important for future studies to utilize sampling procedures that are more inclusive of gender, ethnicity, age, and level of education. A second limitation to consider is that only a limited number of constructs were evaluated from health behavior theories. For instance, perceived behavioral control was not evaluated, which is a construct that is part of an updated version of the theory of reasoned action, the theory of planned behavior (Ajzen, 1985). However, such a variable appears to be more relevant to protective health behaviors, therefore its substantive contribution to examining models of UV exposure and the design of interventions is not entirely clear. Other variables may be more relevant, such as barriers to UV exposure (health belief model; Rosenstock, 1974). A third limitation to consider is that the relationships among constructs posited in the tested models are based on presumed causal relationships. An important area for future research is experimental studies investigating relationships among psychosocial constructs and UV exposure variables, such as single component interventions, which would not only provide evidence of causality, but also efficacy of individual components. A fourth limitation is that skin cancer risk was modeled in term of frequency of exposure. To the extent that risk depends on other factors, such as length of exposure and protection, the extent of the risk will be inaccurate. Moreover, the use of self-report as opposed to more objective measures of UV exposure, such as skin reflectance or personal dosimetry (Glanz \& Mayer, 2005), should also be considered a limitation to quantifying risk. Finally, missing data due to attrition should be considered a potential limitation. If the missing data do not meet the MAR assumption presumed in this study, bias parameter estimates are likely. However, it has been suggested that the amount of bias will be less under direct maximum likelihood (the approach taken in this study) than other missing data treatments, such as listwise deletion (Muthen et al., 1987). Future research should work towards developing a better understanding and prevention of behaviors that place people at risk for developing skin-cancer. 


\section{Footnotes}

${ }^{1}$ One reviewer raised the issue of item bias in the subscales related to evaluating a tan appearance, such that item wordings contaminated the construct of interest with intentions, leading to a possible upward bias in the association between these subscales and intentions. To evaluate this possibility, new subscales were constructed by deleting items with potential bias (6 items deleted from the general factor: 2,3,4,6,8,9; 1 item deleted from the acne factor: 13; 2 items deleted from the aging factor: 31, 32; 2 items deleted from the media factor: 34, 39; 1 item deleted from the family factor: 47) (for the items see appendix). Next, the correlations between each revised subscale and intentions to sunbathe and indoor tan were evaluated. These were compared to the same correlations using the subscales without deleted items. The differences between these correlation coefficients for sunbathing (left of slash) and indoor tanning (right of slash) were: $.039 * / .019, .019 * / .019 *, .015 / .032, .002 / .013 *$, and .005/.002 for general, acne, aging, media, and family, respectively ( $*$ indicates $p<.05$ for a test of difference of dependent correlation coefficients; Chen \& Popovich, 2002). Despite the significance in some cases, the magnitude of these differences is quite small, suggesting little bias, if bias is indeed the cause of the difference in the correlations (smaller correlations could be due to decreased validity resulting from item deletion). Nevertheless, analyses were conducted both including and excluding the specified items, with virtually identical results for comparable indexes and results of significance tests (cf. Tables 3 vs. 4, Tables 6 vs. 7, Figures 6 vs. 7). Interpretation of results is based on results excluding the specified items. ${ }^{2}$ Missing at random (MAR) is an assumption that the probability of missing data on the variable of interest is not related to scores on that variable, controlling for other variables in the model (Little \& Rubin, 1987). Missing completely at random (MCAR) is a stricter assumption that requires the probability of missing data to be unrelated to any variables in the model (Little \& Rubin, 1987).

${ }^{3}$ Strictly speaking, these are not tests of the MCAR assumption, they are tests of homogeneity, which can be used to falsify the MCAR assumption (Kim \& Bentler, 2002). That is, if the results suggest that the groups are not homogeneous, this implies a rejection of MCAR. However, acceptance of homogeneity does not prove that the data are MCAR.

${ }^{4}$ Unreliability was based on one minus the estimate of its test-retest reliability (see Table 1).

${ }^{5}$ Results are based on listwise deleted data.

${ }^{6}$ If a Bonferroni adjustment to the nominal alpha is based on the number of tests for both the direct and indirect effects $(.05 / 20=.0025)$, the decisions regarding statistical significance are identical. If a Bonferroni adjustment to the nominal alpha is based on the number of tests for the alternative models, direct, and indirect effects $(.05 / 29=.0017)$, the decisions regarding statistical significance are the same except entry 3 in Table 7. However, a Bonferroni adjustment is overly strict when the tests are dependent. If even a 
relatively small amount of dependency is assumed (average $r=.20$ ) when calculating the nominal alpha for the 29 tests, the result would be .003 using the Dubey and ArmitageParmar method (Sankoh, Huque, \& Dubey, 1997) and entry 3 in Table 7 would be significant. 


\section{References}

Allison, P.D. (2001). Missing data. Thousand Oaks, CA: Sage Publications.

Allison, P.D.(2003). Missing data techniques for structural equation modeling. Journal of Abnormal Psychology, 112, 545-557.

Ajzen, I. (1985). From intentions to actions: A theory of planned behavior. In J. Kuhl \& J. Beckman (Eds.), Action-control: From cognition to behavior (pp. 11- 39). Heidelberg, Germany: Springer.

Ajzen I, Fishbein M. (1980). Understanding Attitudes and Predicting Social Behavior. Englewood Cliffs, NJ: Prentice-Hall.

American Cancer Society (2007). Cancer facts and figures. Atlanta, GA: Author.

Arbuckle, J.L. (2005). Amos 6.0 User’s Guide. Spring House, PA; Amos Development Corporation.

Arbuckle, J.L. (1996). Full information estimation in the presence of incomplete data. In G.A. Marcoulides and R.E. Schumacker (Ed.s), Advanced Structural Equation Modeling (pp. 243- 277). Mahweh, NJ: Lawrence Erlbaum Associates.

Bollen, K., \& Lennox, R. (1991). Conventional wisdom on measurement: A structural equation perspective. Psychological Bulletin, 110, 305-314.

Browne, M.W. \& Cudeck, R. (1987). Single sample cross-validation indices of covariance structures. Multivariate Behavioral Research, 24, 445-455.

Cafri, G., Thompson, J. K., \& Jacobsen, P. (2006). Appearance reasons for tanning mediate the relationship between media influence and UV exposure and protection. Archives of Dermatology, 142, 1067-1069

Cafri, G., Thompson, J.K., Roehrig, M., Rojas, A., Sperry, S., Jacobsen, P., Hillhouse, J.J. (in press). Appearance Motives to Tan and Not Tan: Evidence for Validity and Reliability of A New Scale. Annals of Behavioral Medicine. 
Cafri, G., Thompson, J.K., Roehrig, M., van den Berg, P., Jacobsen, P.B. \& Stark, S. (2006). An Investigation of Appearance Motives for Tanning: The Development and Evaluation of the Physical Appearance Reasons for Tanning Scale (PARTS) and Its Relation to Sunbathing and Indoor Tanning Intentions. Body Image, 3, 199-209.

Chen, P.Y., \& Popovich, P.M. (2002). Correlation: Parametric and nonparametric measures. Thousand Oaks, CA: Sage.

Curran, P.J., West, S.G., \& Finch, J.F. (1996). The robustness of test statistics to nonnormality and specification error in confirmatory factor analysis. Psychological Methods, 1, 16-29.

Davis, K.J., Cokkinides, V.E., Weinstock, M.A., O’Connell, M.C., \& Wingo, P.A. (2002). Summer sunburn and sun exposure among U.S. youths ages 11 to 18 : National prevalence and associated factors. Pediatrics, 110, 27-35.

Demko, C.A.; Borawski, E.A., Debanne, S.M., Cooper K.D., Stange, K.C. (2003). Use of indoor tanning facilities by white adolescents in the United States. Archives of Pediatric and Adolescent Medicine, 157, 854-860.

Fishbein, M. (2000). The role of theory in HIV prevention. Aids Care, 12, 273-278.

Fitzpatrick, T.B. (1988). The validity and practicality of sun-reactive skin types I through VI. Archives of Dermatology, 124, 869-871.

Gibbons, F.X., Gerrard, M., Lane, D.J., Mahler, H.I.M., \& Kulik, J.A. (2005). Using UV photography to reduce use of tanning booths: A test of cognitive mediation. Health Psychology, 24, 358 - 363.

Glanz, K. \& Mayer, J.A. (2005). Reducing ultraviolet radiation exposure to prevent skin cancer: Methodology and measurement. American Journal of Preventive Medicine, 29, 131-142.

Goldsmith, M.F. (1987). Paler is better, say skin cancer fighters. Journal of the American Medical Association, 257, 893-894.

Hillhouse, J.J., Adler, C.M., Drinnon, J., \& Turrisi, R. (1997). Application of Azjen’s theory of planned behavior to predict sunbathing, tanning salon use, and sunscreen use intentions and behaviors. Journal of Behavioral Medicine, 20, 365378.

Hillhouse, J.J., Stair, A.W., \& Adler, C.M. (1996). Predictors of sunbathing and sunscreen use in college undergraduates. Journal of Behavioral Medicine, 19, 543-560. 
Hillhouse, J.J. \& Turrisi, R. (2002). An examination of the efficacy of an appearancefocused intervention to reduce UV exposure. Journal of Behavioral Medicine, 25, 395-409.

Hillhouse, Turrisi, Holwiski \& McVeigh, (1999). An examination of psychological variables relevant to artificial tanning tendencies. Journal of Health Psychology, 4, 507-516.

Hillhouse, J.J., Turrisi, R., Kastner, M. (2000). Modeling Tanning Salon Behavioral Tendencies Using Appearance Motivation, Self-Monitoring, and the Theory of Planned Behavior. Health Education Review, 15, 405- 414.

Hu, L. \& Bentler, P. M. (1998). Fit indices in covariance structure modeling: Sensitivity to underparameterized model misspecification. Psychological Methods, 3, 424453.

Hu, L., \& Bentler, P. M. (1999). Cutoff criteria for fit indexes in covariance structure analysis: Conventional criteria versus new alternatives. Structural Equation Modeling, 6, 1-55.

Jackson, K.M. \& Aiken, L. S. (2000). A psychosocial model of sun protection and sunbathing in young women: The impact of health beliefs, attitudes, norms, and self-efficacy for sun protection. Health Psychology, 19, 469-478.

Jones, J.L., \& Leary, M.R. (1994). Effects of appearance-based admonitions against sun exposure on tanning intentions in young adults. Health Psychology, 13, 86-90.

Kim, K.H., Bentler, P.M. (2002). Tests of homogeneity of means and covariance matrices for multivariate incomplete data. Psychometrika, 67, 609-624.

Lazovich, D., Forster, J., Sorensen, G., Emmons, K., Stryker, J., Demierre, M.F., Hickle, A.H., Remba, N. (2004). Characteristics associated with use or intention to use indoor tanning among adolescents. Archives of Pediatrics \& Adolescent Medicine, 158, 918-924.

Little, R.J.A. (1987). A test of missing completely at random for multivariate data with missing values. Journal of the American Statistical Association, 83, 1198-1202.

Little, R.J.A., Rubin, D.B. (1987). Statistical Analysis with Missing Data. New York: Wiley \& Sons.

MacCallum, R.C., Browne, M.W., \& Sugawara, H.M. (1996). Power analysis and determination of sample size for covariance structural modeling. Psychological Methods, 1, 130-149. 
Mahler, H.I., Kulik, J.A., Gibbons, F.X., Gerrard, M. \& Harrell, J. (2003). Effects of appearance-based interventions on sun protection intentions and self-reported behaviors. Health Psychology, 22, 199-209.

Mahler, H.I.M, Kulik, J.A, Harrell, J., Correa, A., Gibbons, F. X. \& Gerrard, M. (2005). Effects of UV photographs, photoaging information, and use of sunless tanning lotion on sun protection behaviors. Archives of Dermatology, 141, 373-380.

Muthen, B., Kaplan, D., \& Hollis, M. (1987). On structural equation modeling with data that are not missing completely at random. Psychometrika, 52, 431-462.

Rogers, R.W. (1983) A protection motivation theory of fear appeals and attitude change: A revised theory of protection motivation. In J.R. Cacioppo \& R.E. Petty (Eds.) Social psychology: A sourcebook (pp.153-176). New York: Guilford press.

Rosenstock, I.M. (1974). The health belief model and preventive health behavior. Health education monographs, 2, 354-386.

Sankoh, A.J., Huque, M.F., \& Dubey, S.D. (1997). Some comments on frequently used multiple endpoint adjustment methods in clinical trials. Statistics in Medicine, 16, 2529-2542.

Sobel, M.E. (1982). Asymptotic confidence intervals for indirect effects in structural equation models. In S. Leinhardt (Ed.), Sociological Methodology (pp.290-312). Washington, DC: American Sociological Association.

Stice, E., Trost, A., \& Chase, A. (2003). Healthy weight control and dissonance-based eating disorder prevention programs: Results from a controlled trial. International Journal of Eating Disorders, 33, 10-21.

Taylor, A.B., Mackinnon, D.P., Tein, J. (in press). Tests of the three-path mediated effect. Organizational Research Methods.

Thompson, J.K., Heinberg, L., Altabe, M., \& Tantleff-Dunn, S. (1999). Exacting Beauty. Washington, DC; American Psychological Association.

Turrisi, R. Hillhouse, J. \& Gebert, C. (1998). Examination of cognitive variables relevant to sunbathing. Journal of Behavioral Medicine, 21, 299-313.

U.S. Department of Health and Human Services. Ultraviolet radiation-related exposures: broad spectrum ultraviolet (UV) radiation, UVA, UVB, UVC, solar radiation, and exposure to sunlamps and sunbeds. In the Tenth Annual Report on Carcinogens (2002). Retrieved August $27^{\text {th }}$, 2004 from http://ehis.niehs.nih.gov/roc/tenth/profiles/s183uvrr.pdf 
Weinstock, M.A. (1992). Assessment of sun sensitivity by questionnaire: Validity of items and formulation of a prediction rule. Journal of Clinical Epidemiology, 45, 547-552.

West, S.G., Finch, J.F., \& Curran, P.J. (1995). Structural equation modeling with nonnormal variables: Problems and remedies. In R.H. Hoyle (Ed.). Structural equation modeling: Concepts issues and applications (pp.56-75). Thousand Oaks, CA: Sage.

Wichstrom, L. (1994). Predictors of Norwegian adolescents' sunbathing and use of sunscreen. Health Psychology, 13, 412-4. 
Appendices 
Appendix A: Scale Items

\section{APPEARANCE REASONS TO TAN}

General

1. Having a tan gives me more sex appeal.

2. I tan because it makes me more attractive.

3. I tan because it makes me look better.

4. I tan because it makes me more confident in my appearance.

5. I feel more confident in my appearance when I am tan.

6. I tan before a big social event because it makes me feel more attractive.

7. The tanner I am, the more attractive I feel.

8. I tan to avoid looking pale.

9. I tan because it adds a nice glow to my appearance.

Acne

11. When I am tan, I feel less concerned about the appearance of acne.

12. The less tan I am the more I'm worried about my acne showing.

13. I tan because it helps reduce the amount of acne on my face and body.

14. Tan skin helps me cover up acne-related scars.

Body shape

16. I look like I have less fat on my body when I am tan.

17. The more tan I am the more physically fit I look.

19. A tan gives my body the appearance of having more muscle tone.

20. A tan helps me look like I'm in good physical shape.

23. I look slimmer with a tan.

24. Being tan conceals my appearance of stretch marks.

Immediate Skin Damage

\section{APPEARANCE REASONS NOT TO TAN}

25. I'm concerned about getting blemished skin as a result of tanning.

26. I'm concerned about freckling from tanning.

27. The appearance of a sunburn makes me look unattractive.

28. Getting sunspots worries me.

29. I'm concerned about my skin peeling after too much tanning.

30. I'm concerned about the appearance of rough or leathery skin from tanning.

Aging

31. I don't tan as much as I would like because I'm worried about premature skin aging.

32. I don't tan because it will age my skin quicker.

33. I'm hesitant to tan because it will wrinkle my skin. 
Appendix A: (Continued)

\section{SOCIOCULTURAL INFLUENCES}

$\underline{\text { Media }}$

34. I try to have a tan like famous people I see in magazines.

35. I wish I was as tan as celebrities in the media.

36. I want to be as tan as TV stars.

37. I wish I had a tan like people on TV.

38. I want to be as tan as people in magazines.

39. I try to be as tan as people in movies.

41. I would like my skin tone to be darker like people in TV and movies.

Friends

42. I like to be as tan as my friends.

43. Positive appearance comments from my friends make me want to tan more.

44. I receive negative appearance comments from my friends when I am not tan.

45. My friends say I look good when I am tan.

Family

46. I want a tan because people in my family think it makes my skin look nice.

47. I try to get a tan because my family members say it is attractive.

48. I want to be tan because my family members think it makes me look healthier.

Significant Other

49. My boyfriend/girlfriend likes the way I look when I am tan.

50. Comments about my appearance from my boyfriend/girlfriend encourage me to tan.

Perceived Susceptibility

\section{PERCEIVED THREAT}

51. If you DON'T use sun protection, how susceptible do you feel you are to skin cancer?

52. The possibility of skin cancer worries me.

53. Whenever I hear of a friend or relative (or public figure) getting skin cancer, it makes me realize that I could get it too.

54. I don't need to worry about getting skin cancer until I am much older.

Perceived Severity

55. It would be terrible to get a malignant tumor on my skin.

56. Getting skin cancer would severely affect my life.

57. It would be terrible to have skin cancer.

\section{TANNING INTENTIONS AND BEHAVIORS}

58. Please give me your best estimate of how many times you have indoor tanned in the last 6 months

59. Please give me your best estimate of how many times you have sunbathed in the last $\underline{6 \text { months }}$

60. Please give me your best estimate of how many times you plan to use an indoor tanning salon in the next 6 months 
Appendix A: (Continued)

61. Please give me your best estimate of how many times you plan to sunbathe in the next $\underline{6 \text { months }}$

\section{SKIN CANCER RISK (SKIN TYPE)}

62. If you were to lie in the sun for one hour UNPROTECTED (no sunscreen, no protective clothing, etc.) in the early summer when you had NO tan, your skin would: (mark the best answer)

63. What is the color of your untanned skin? 
Appendix B: Tables and Figures

Table 1. Means, Standard Deviations, and Reliability of Scales 
Appendix B: (Continued)

\begin{tabular}{|c|c|c|c|c|c|c|c|c|}
\hline \multirow[t]{2}{*}{ Factor } & \multirow[t]{2}{*}{ Items } & \multirow[t]{2}{*}{ Mean } & \multirow[t]{2}{*}{ SD } & \multirow[t]{2}{*}{$\alpha$} & \multirow[t]{2}{*}{$\begin{array}{l}\text { Test- } \\
\text { Retest } \\
r\end{array}$} & \multicolumn{3}{|c|}{$\begin{array}{l}\text { Attrition Analyses } \\
\text { Completers vs. } \\
\text { Non-Completers }\end{array}$} \\
\hline & & & & & & $\begin{array}{c}t- \\
\text { value }\end{array}$ & $\begin{array}{c}p- \\
\text { value }\end{array}$ & $d$ \\
\hline $\begin{array}{l}\text { Appearance Reasons } \\
\text { to Tan }\end{array}$ & 19 & 3.30 & .96 & .96 & .91 & - & - & - \\
\hline General & & & & .95 & & 3.47 & .001 & \\
\hline Attractiveness & 9 & 3.60 & 1.06 & & .94 & & & .28 \\
\hline Acne & 4 & 2.77 & 1.18 & .91 & .80 & 1.47 & 143 & .12 \\
\hline Body shape & 6 & 3.23 & 1.11 & .92 & .88 & .884 & .377 & .07 \\
\hline Appearance Reasons & 9 & 3.14 & .81 & .82 & & & & \\
\hline $\begin{array}{l}\text { Not to Tan } \\
\text { Immediate Skin }\end{array}$ & & & & .83 & .86 & - & - & - \\
\hline Damage & 6 & 3.19 & .83 & & .87 & 1.19 & 233 & 10 \\
\hline $\begin{array}{l}\text { Skin Aging } \\
\text { Sociocultural }\end{array}$ & 3 & 3.05 & 1.06 & $\begin{array}{l}.73 \\
.94\end{array}$ & .75 & .036 & .972 & .00 \\
\hline Influences to Tan & 16 & 2.58 & .91 & & .93 & - & - & - \\
\hline Media & 7 & 2.31 & 1.14 & .97 & .89 & 1.14 & 253 & .09 \\
\hline Family & 3 & 2.39 & 1.15 & .77 & .81 & 2.12 & .035 & .17 \\
\hline Friends & 4 & 2.96 & 0.95 & .91 & .88 & 2.49 & .013 & .21 \\
\hline Significant Other & 2 & 3.10 & 1.19 & .86 & .85 & 1.94 & .053 & .16 \\
\hline $\begin{array}{l}\text { Perceived } \\
\text { Susceptibility-Skin }\end{array}$ & & & & .71 & & & & \\
\hline $\begin{array}{l}\text { Cancer } \\
\text { Perceived Severity- }\end{array}$ & 4 & 3.46 & .50 & .89 & .82 & 1.15 & 251 & .09 \\
\hline Skin Cancer & 3 & 4.62 & .66 & & .79 & 2.82 & .005 & .23 \\
\hline $\begin{array}{l}\text { Skin Cancer Risk- } \\
\text { Fitzpatrick Skin Type }\end{array}$ & & & & - & & & & \\
\hline & 1 & 2.76 & .97 & & .92 & 1.28 & 202 & .11 \\
\hline Skin Cancer Risk- & 1 & 1.47 & .53 & - & & & & \\
\hline Untanned Skin ${ }^{\mathrm{b}}$ & & & & & .68 & - & - & - \\
\hline $\begin{array}{l}\text { Indoor Tanning } \\
\text { Intentions (6 month }\end{array}$ & 1 & $\begin{array}{c}1.99 / \\
7.86\end{array}$ & $\begin{array}{l}1.33 / \\
15.31\end{array}$ & - & & .57 & .570 & \\
\hline frequency) $^{\mathrm{c}}$ & & & & & .92 & & & .05 \\
\hline $\begin{array}{l}\text { Sunbathing Intentions } \\
\left(6 \text { month frequency) }{ }^{c}\right.\end{array}$ & 1 & $\begin{array}{l}2.40 / \\
10.43\end{array}$ & $\begin{array}{l}1.17 / \\
11.07\end{array}$ & - & .89 & .61 & .541. & .05 \\
\hline $\begin{array}{l}\text { Indoor Tanning } \\
\text { Behaviors (6 month } \\
\text { frequency) }^{\mathrm{c}}\end{array}$ & 1 & $\begin{array}{c}1.83 / \\
6.57\end{array}$ & $\begin{array}{l}1.37 / \\
12.65\end{array}$ & - & .96 & - & - & - \\
\hline 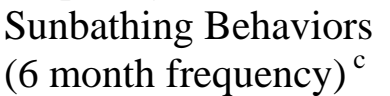 & 1 & $\begin{array}{c}2.38 / \\
9.93\end{array}$ & $\begin{array}{l}1.02 / \\
9.49\end{array}$ & - & .80 & - & - & - \\
\hline
\end{tabular}


Appendix B: (Continued)

Note: Means and standard deviation values for multi-item Likert scales expressed as item averages. ${ }^{a}$ The direction of the results for all but indoor tanning intentions is such that completers had higher scores than non-completers. ${ }^{\mathrm{b}}$ Internal consistency for the two skin cancer risk items is .62. Attrition analyses based on a single variable consisting of the two skin cancer risk items recoded (such that higher scores indicate more risk), standardized, then summed. ${ }^{\text {c }}$ For the UV exposure items, values to the left of the slash are based on the response scale, values to the right are in frequency units. Frequency units were obtained by using the midpoint of the interval specified for each response value. For sunbathing intentions, $82.7 \%$ of the sample planned to sunbathe and $52.8 \%$ planned to indoor tan at least once during the upcoming 6 month period. Among the individuals followed up after the 6 months, $86.7 \%$ of the sample reported sunbathing and $39.3 \%$ reported indoor tanning at least once. 
Appendix B: (Continued)

Table 2. Correlations Among Scales

\begin{tabular}{lccccccccc}
\hline & 1 & 2 & 3 & 4 & 5 & 6 & 7 & 8 & 9 \\
\hline $\begin{array}{l}\text { 1. Appearance Reasons } \\
\text { to Tan }\end{array}$ & - & & & & & & & & \\
2. Appearance Reasons & & & & & & & & & \\
Not to Tan & .08 & - & & & & & & & \\
3. Sociocultural & & & & & & & & & \\
Influences to Tan & .74 & .09 & - & & & & & & \\
4. Perceived Threat & .12 & .44 & .01 & - & & & & & \\
5. Skin Cancer Risk & -.01 & .24 & .04 & .17 & - & & & & \\
6. Indoor Tanning & & & & & & & & & \\
Intentions & .35 & -.13 & .30 & -.08 & -.04 & - & & & \\
7. Sunbathing Intentions & .32 & -.15 & .21 & .04 & -.12 & .20 & - & & \\
8. Indoor Tanning & & & & & & & & & \\
Behaviors & .26 & -.14 & .22 & -.10 & -.09 & .61 & .21 & - & \\
9. Sunbathing Behaviors & .23 & -.15 & .12 & -.01 & -.09 & .09 & .62 & .14 & - \\
\hline
\end{tabular}

Note: Skin cancer risk variable is as described in the Note in Table 1. Perceived threat is a composite based on unit weights for perceived susceptibility and severity subscales. 
Appendix B: (Continued)

Table 3. Tests of Alternative Models (without item deletion)

\begin{tabular}{|c|c|c|c|c|c|c|c|}
\hline Model & Description & $\chi^{2}$ & $d f$ & $\Delta \chi^{2 a}$ & $\Delta d f^{a}$ & AIC & $B C C$ \\
\hline & Measurement Model & 3294.61 & 1499 & - & - & 3716.61 & 3762.19 \\
\hline \multicolumn{8}{|c|}{ Role of Intentions and Behaviors } \\
\hline $1 \mathrm{a}$ & Figure $1+$ Figure $2^{b}$ & 3344.51 & 1517 & - & - & 3730.51 & 3772.20 \\
\hline $1 \mathrm{~b}$ & Figure 1 & 3350.32 & 1523 & 5.81 & 6 & 3724.32 & 3764.71 \\
\hline 1c & $\begin{array}{l}\text { Figure } 2 \text { (excluding } \\
\text { dashed paths) }\end{array}$ & 3819.64 & 1525 & $475.13^{*}$ & 8 & 4189.64 & 4229.60 \\
\hline $1 \mathrm{~d}$ & $\begin{array}{l}\text { Figure } 2 \text { (including } \\
\text { dashed paths) }\end{array}$ & 3587.67 & 1523 & $243.16^{*}$ & 6 & 3961.67 & 4002.07 \\
\hline \multicolumn{8}{|c|}{ Role of Sociocultural Influences } \\
\hline $2 \mathrm{a}$ & Figure $1+$ Figure $3^{b}$ & 3345.98 & 1521 & - & - & 3723.98 & 3764.80 \\
\hline $2 b$ & Figure 1 & 3350.32 & 1523 & 4.34 & 2 & 3724.32 & 3764.71 \\
\hline $2 c$ & Figure 3 & 4036.35 & 1522 & 686.03* & 1 & 4412.35 & 4452.96 \\
\hline \multicolumn{8}{|c|}{ Role of Perceived Susceptibility } \\
\hline 3a & Figure 1 & 3350.32 & 1523 & & - & 3724.32 & 3764.71 \\
\hline $3 \mathrm{~b}$ & $\begin{array}{l}\text { Figure } 4 \text { (excluding } \\
\text { light dashed paths) }\end{array}$ & 3451.41 & 1525 & $101.09 *$ & 2 & 3821.41 & 3861.37 \\
\hline $3 c$ & $\begin{array}{l}\text { Figure } 4 \text { (excluding } \\
\text { heavy dashed paths) }\end{array}$ & 3359.32 & 1525 & 9.00 & 2 & 3729.32 & 3769.30 \\
\hline \multicolumn{8}{|c|}{ Role of Skin Cancer Risk } \\
\hline $4 a$ & $\underset{b}{\operatorname{Model} 3 c+\text { Figure } 5}$ & 3358.38 & 1523 & - & - & 3732.38 & 3772.78 \\
\hline $4 \mathrm{~b}$ & Model 3c & 3359.32 & 1525 & .94 & 2 & 3729.32 & 3769.30 \\
\hline $4 \mathrm{c}$ & Figure 5 & 3389.23 & 1524 & $30.85^{*}$ & 1 & 3761.23 & 3801.41 \\
\hline
\end{tabular}

* Indicates the value is significant at $p<.0056$ (Bonferroni adjustment $=.05 / 9$ ). AIC= Akaike information criterion. $\mathrm{BCC}=$ Browne-Cudeck criterion. ${ }^{\mathrm{a}}$ All comparisons of nested models are based on comparing saturated models, "a" model in a given number class, with more constrained models "b-d" in the same number class. ${ }^{\mathrm{b}}$ In 1a, 2a and 4a, the models consist of the model to left of the plus sign and the non-overlapping paths from the model to the right of the plus sign. 
Appendix B: (Continued)

Table 4. Tests of Alternative Models (with item deletion)

\begin{tabular}{|c|c|c|c|c|c|c|c|}
\hline Model & Description & $\chi^{2}$ & $d f$ & $\Delta \chi^{2 a}$ & $\Delta d f^{a}$ & AIC & $B C C$ \\
\hline & Measurement Model & 2099.99 & 907 & - & - & 2445.99 & 2474.99 \\
\hline \multicolumn{8}{|c|}{ Role of Intentions and Behaviors } \\
\hline $1 \mathrm{a}$ & Figure $1+$ Figure $2^{b}$ & 2146.55 & 924 & & - & 2458.55 & 2484.69 \\
\hline $1 b$ & Figure 1 & 2152.17 & 930 & 5.62 & 6 & 2452.17 & 2477.31 \\
\hline $1 \mathrm{c}$ & $\begin{array}{c}\text { Figure } 2 \text { (excluding } \\
\text { dashed paths) }\end{array}$ & 2607.88 & 932 & 461.33* & 8 & 2903.88 & 2928.68 \\
\hline $1 \mathrm{~d}$ & $\begin{array}{l}\text { Figure } 2 \text { (including } \\
\text { dashed paths) }\end{array}$ & 2369.54 & 930 & 222.99* & 6 & 2669.54 & 2694.67 \\
\hline \multicolumn{8}{|c|}{ Role of Sociocultural Influences } \\
\hline $2 \mathrm{a}$ & Figure $1+$ Figure $3^{b}$ & 2149.56 & 928 & - & - & 2453.56 & 2479.04 \\
\hline $2 b$ & Figure 1 & 2152.17 & 930 & 2.61 & 2 & 2452.17 & 2477.31 \\
\hline 2c & Figure 3 & 2810.03 & 929 & $660.47 *$ & 1 & 3112.03 & 3137.33 \\
\hline \multicolumn{8}{|c|}{ Role of Perceived Susceptibility } \\
\hline 3a & Figure 1 & 2152.17 & 930 & - & - & 2452.17 & 2477.31 \\
\hline $3 b$ & $\begin{array}{l}\text { Figure } 4 \text { (excluding } \\
\text { light dashed paths) }\end{array}$ & 2239.07 & 932 & 86.9* & 2 & 2535.07 & 2559.88 \\
\hline $3 c$ & $\begin{array}{l}\text { Figure } 4 \text { (excluding } \\
\text { heavy dashed paths) }\end{array}$ & 2159.01 & 932 & 6.84 & 2 & 2455.01 & 2479.81 \\
\hline \multicolumn{8}{|c|}{ Role of Skin Cancer Risk } \\
\hline $4 a$ & Model 3c+ Figure $5^{b}$ & 2158.01 & 930 & - & - & 2458.01 & 2483.14 \\
\hline $4 \mathrm{~b}$ & Model 3c & 2159.01 & 932 & 1 & 2 & 2455.01 & 2479.81 \\
\hline 4c & Figure 5 & 2184.46 & 931 & $26.45 *$ & 1 & 2482.46 & 2507.43 \\
\hline
\end{tabular}

* Indicates the value is significant at $p<.0056$ (Bonferroni adjustment $=.05 / 9$ ). AIC= Akaike information criterion. $\mathrm{BCC}=$ Browne-Cudeck criterion. ${ }^{\mathrm{a}}$ All comparisons of nested models are based on comparing saturated models, "a" model in a given number class, with more constrained models "b-d" in the same number class. ${ }^{\mathrm{b}}$ In 1a, 2a and 4a, the models consist of the model to left of the plus sign and the non-overlapping paths from the model to the right of the plus sign. 
Appendix B: (Continued)

Table 5. Tests of Alternative Models (outliers deleted)

\begin{tabular}{|c|c|c|c|c|c|c|c|}
\hline Model & Description & $\chi^{2}$ & $d f$ & $\Delta \chi^{2 a}$ & $\Delta d f^{a}$ & AIC & $B C C$ \\
\hline & $\begin{array}{l}\text { Measurement } \\
\text { Model }\end{array}$ & 3284.65 & 1499 & - & - & 3706.65 & 3752.66 \\
\hline \multicolumn{8}{|c|}{ Role of Intentions and Behaviors } \\
\hline $1 \mathrm{a}$ & $\begin{array}{l}\text { Figure } 1+\text { Figure } \\
2^{b}\end{array}$ & 3335.50 & 1517 & - & - & 3721.50 & 3763.59 \\
\hline $1 \mathrm{~b}$ & Figure 1 & 3341.19 & 1523 & 5.69 & 6 & 3715.19 & 3755.97 \\
\hline $1 \mathrm{c}$ & $\begin{array}{c}\text { Figure } 2 \\
\text { (excluding } \\
\text { dashed paths) }\end{array}$ & 3805.87 & 1525 & $\begin{array}{c}470.37 \\
*\end{array}$ & 8 & 4175.87 & 4216.21 \\
\hline $1 \mathrm{~d}$ & $\begin{array}{l}\text { Figure } 2 \\
\text { (including } \\
\text { dashed paths) }\end{array}$ & 3578.36 & 1523 & $\begin{array}{c}242.86 \\
*\end{array}$ & 6 & 3952.36 & 3993.14 \\
\hline \multicolumn{8}{|c|}{ Role of Sociocultural Influences } \\
\hline $2 a$ & $\begin{array}{c}\text { Figure 1+ Figure } \\
3^{b}\end{array}$ & 3336.87 & 1521 & - & - & 3714.87 & 3756.08 \\
\hline $2 \mathrm{~b}$ & Figure 1 & 3341.19 & 1523 & 4.32 & 2 & 3715.19 & 3755.97 \\
\hline $2 c$ & Figure 3 & 4020.07 & 1522 & $683.2 *$ & 1 & 4396.07 & 4437.06 \\
\hline \multicolumn{8}{|c|}{ Role of Perceived Susceptibility } \\
\hline $3 a$ & Figure 1 & 3341.19 & 1523 & - & - & 3715.19 & 3755.97 \\
\hline $3 b$ & $\begin{array}{c}\text { Figure } 4 \\
\text { (excluding light } \\
\text { dashed paths) }\end{array}$ & 3439.13 & 1525 & 97.94* & 2 & 3809.13 & 3849.47 \\
\hline $3 c$ & $\begin{array}{c}\text { Figure } 4 \\
\text { (excluding heavy } \\
\text { dashed paths) }\end{array}$ & 3350.77 & 1525 & 9.58 & 2 & 3720.77 & 3761.11 \\
\hline \multicolumn{8}{|c|}{ Role of Skin Cancer Risk } \\
\hline $4 a$ & $\begin{array}{l}\text { Model 3c + } \\
\text { Figure } 5^{b}\end{array}$ & 3349.45 & 1523 & - & - & 3723.45 & 3764.22 \\
\hline $4 \mathrm{~b}$ & Model 3c & 3350.77 & 1525 & 1.32 & 2 & 3720.77 & 3761.11 \\
\hline $4 c$ & Figure 5 & 3380.95 & 1524 & $31.5^{*}$ & 1 & 3752.95 & 3793.51 \\
\hline
\end{tabular}

* Indicates the value is significant at $p<.0056$ (Bonferroni adjustment $=.05 / 9$ ). AIC= Akaike information criterion. BCC $=$ Browne-Cudeck criterion. ${ }^{\text {a }}$ All comparisons of nested models are based on comparing saturated models, "a" model in a given number class, with more constrained models "b-d" in the same number class. ${ }^{\mathrm{b}}$ In 1a, 2a and 4a, the models consist of the model to left of the plus sign and the non-overlapping paths from the model to the right of the plus sign. 
Appendix B: (Continued)

Table 6. Tests of Indirect Effects (without item deletion)

\begin{tabular}{|c|c|c|c|c|c|}
\hline Origin & $\begin{array}{c}\text { Standardized } \\
\text { Indirect } \\
\text { Effect } \\
\end{array}$ & $\begin{array}{c}\text { Unstandardized } \\
\text { Indirect } \\
\text { Effect }\end{array}$ & $S E$ & $Z$ & $p$ \\
\hline & \multicolumn{5}{|c|}{ Sunbathing Behaviors } \\
\hline $\begin{array}{l}\text { 1. Sociocultural Influences } \\
\text { to Tan (3 paths) }\end{array}$ & 0.28 & 0.11 & 0.02 & 5.34 & $<.001^{*}$ \\
\hline 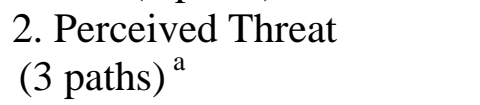 & 0.01 & 0.00 & 0.01 & 0.69 & .315 \\
\hline $\begin{array}{l}\text { 3. Perceived Threat } \\
\text { (3 paths) }\end{array}$ & 0.11 & 0.07 & 0.02 & 3.60 & $<.001^{*}$ \\
\hline $\begin{array}{l}\text { 4. Appearance Reasons to } \\
\text { Tan ( } 2 \text { paths) }\end{array}$ & 0.31 & 0.09 & 0.01 & 7.81 & $<.001^{*}$ \\
\hline \multirow[t]{2}{*}{$\begin{array}{l}\text { 5. Appearance Reasons } \\
\text { Not to Tan ( } 2 \text { paths) }\end{array}$} & 0.15 & 0.05 & 0.01 & 4.32 & $<.001^{*}$ \\
\hline & \multicolumn{5}{|c|}{ Indoor Tanning Behaviors } \\
\hline $\begin{array}{l}\text { 6. Sociocultural Influences } \\
\text { to Tan ( } 3 \text { paths) }\end{array}$ & 0.28 & 0.16 & 0.02 & 6.99 & $<.001^{*}$ \\
\hline $\begin{array}{l}\text { 7. Perceived Threat } \\
(3 \text { paths })^{\mathrm{a}}\end{array}$ & 0.01 & 0.01 & 0.01 & 0.69 & .314 \\
\hline 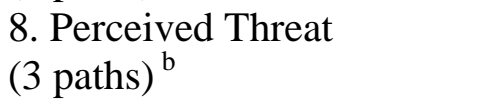 & 0.11 & 0.10 & 0.03 & 3.81 & $<.001^{*}$ \\
\hline $\begin{array}{l}\text { 9. Appearance Reasons to } \\
\text { Tan ( } 2 \text { paths })\end{array}$ & 0.30 & 0.12 & 0.01 & 8.32 & $<.001^{*}$ \\
\hline $\begin{array}{l}\text { 10. Appearance Reasons } \\
\text { Not to Tan ( } 2 \text { paths) }\end{array}$ & 0.15 & 0.07 & 0.01 & 4.69 & $<.001^{*}$ \\
\hline
\end{tabular}

* Significant after a Bonferroni adjustment to the nominal alpha $(.05 / 10=.005){ }^{a}$ Through appearance reasons to tan. ${ }^{\mathrm{b}}$ Through appearance reasons not to tan. 
Appendix B: (Continued)

Table 7. Tests of Indirect Effects (with item deletion)

\begin{tabular}{|c|c|c|c|c|c|}
\hline Origin & $\begin{array}{c}\text { Standardized } \\
\text { Indirect } \\
\text { Effect } \\
\end{array}$ & $\begin{array}{c}\text { Unstandardized } \\
\text { Indirect } \\
\text { Effect } \\
\end{array}$ & $S E$ & $Z$ & $p$ \\
\hline & \multicolumn{5}{|c|}{ Sunbathing Behaviors } \\
\hline $\begin{array}{l}\text { 1. Sociocultural Influences } \\
\text { to Tan (3 paths) }\end{array}$ & 0.28 & 0.11 & 0.02 & 5.28 & $<.001 *$ \\
\hline 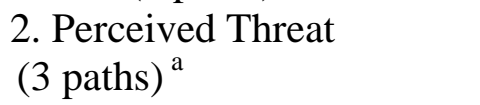 & 0.01 & 0.01 & 0.01 & 1.41 & .147 \\
\hline $\begin{array}{l}\text { 3. Perceived Threat } \\
\text { (3 paths) }\end{array}$ & 0.09 & 0.06 & 0.02 & 3.20 & $.002 *$ \\
\hline $\begin{array}{l}\text { 4. Appearance Reasons to } \\
\text { Tan ( } 2 \text { paths) }\end{array}$ & 0.30 & 0.08 & 0.01 & 7.67 & $<.001^{*}$ \\
\hline \multirow[t]{2}{*}{$\begin{array}{l}\text { 5. Appearance Reasons } \\
\text { Not to Tan (2 paths) }\end{array}$} & 0.14 & 0.07 & 0.02 & 3.86 & $<.001^{*}$ \\
\hline & \multicolumn{5}{|c|}{ Indoor Tanning Behaviors } \\
\hline $\begin{array}{l}\text { 6. Sociocultural Influences } \\
\text { to Tan ( } 3 \text { paths) }\end{array}$ & 0.27 & 0.15 & 0.02 & 6.86 & $<.001^{*}$ \\
\hline $\begin{array}{l}\text { 7. Perceived Threat } \\
(3 \text { paths })^{\mathrm{a}}\end{array}$ & 0.01 & 0.01 & 0.01 & 1.41 & 147 \\
\hline $\begin{array}{l}\text { 8. Perceived Threat } \\
\text { (3 paths) }{ }^{\mathrm{b}}\end{array}$ & 0.10 & 0.09 & 0.03 & 3.43 & $.001 *$ \\
\hline $\begin{array}{l}\text { 9. Appearance Reasons to } \\
\text { Tan ( } 2 \text { paths) }\end{array}$ & 0.29 & 0.11 & 0.01 & 8.12 & $<.001^{*}$ \\
\hline $\begin{array}{l}\text { 10. Appearance Reasons } \\
\text { Not to Tan ( } 2 \text { paths) }\end{array}$ & 0.15 & 0.10 & 0.02 & 4.28 & $<.001 *$ \\
\hline
\end{tabular}

* Significant after a Bonferroni adjustment to the nominal alpha $(.05 / 10=.005){ }^{a}$ Through appearance reasons to tan. ${ }^{\mathrm{b}}$ Through appearance reasons not to tan. 
Appendix B: (Continued)

Table 8. Tests of Indirect Effects (with outliers deleted)

\begin{tabular}{|c|c|c|c|c|c|}
\hline Origin & $\begin{array}{c}\text { Standardized } \\
\text { Indirect } \\
\text { Effect }\end{array}$ & $\begin{array}{c}\text { Unstandardized } \\
\text { Indirect } \\
\text { Effect }\end{array}$ & $S E$ & $Z$ & $p$ \\
\hline & \multicolumn{5}{|c|}{ Sunbathing Behaviors } \\
\hline $\begin{array}{l}\text { 1. Sociocultural Influences } \\
\text { to Tan (3 paths) }\end{array}$ & 0.29 & 0.11 & 0.02 & 5.35 & $<.001^{*}$ \\
\hline 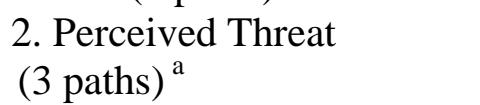 & 0.01 & 0.00 & 0.01 & 0.73 & .305 \\
\hline $\begin{array}{l}\text { 3. Perceived Threat } \\
\text { (3 paths) }\end{array}$ & 0.11 & 0.07 & 0.02 & 3.55 & $<.001^{*}$ \\
\hline $\begin{array}{l}\text { 4. Appearance Reasons to } \\
\text { Tan ( } 2 \text { paths) }\end{array}$ & 0.31 & 0.09 & 0.01 & 7.86 & $<.001 *$ \\
\hline \multirow[t]{2}{*}{$\begin{array}{l}\text { 5. Appearance Reasons } \\
\text { Not to Tan ( } 2 \text { paths) }\end{array}$} & 0.15 & 0.05 & 0.01 & 4.25 & $<.001 *$ \\
\hline & \multicolumn{5}{|c|}{ Indoor Tanning Behaviors } \\
\hline $\begin{array}{l}\text { 6. Sociocultural Influences } \\
\text { to Tan ( } 3 \text { paths) }\end{array}$ & 0.27 & 0.16 & 0.02 & 6.92 & $<.001^{*}$ \\
\hline $\begin{array}{l}\text { 7. Perceived Threat } \\
\text { ( } 3 \text { paths) }^{\text {a }}\end{array}$ & 0.01 & 0.01 & 0.01 & 0.73 & .305 \\
\hline $\begin{array}{l}\text { 8. Perceived Threat } \\
\text { (3 paths) }\end{array}$ & 0.11 & 0.10 & 0.03 & 3.80 & $<.001 *$ \\
\hline $\begin{array}{l}\text { 9. Appearance Reasons to } \\
\text { Tan ( } 2 \text { paths) }\end{array}$ & 0.29 & 0.12 & 0.01 & 8.22 & $<.001 *$ \\
\hline $\begin{array}{l}\text { 10. Appearance Reasons } \\
\text { Not to Tan ( } 2 \text { paths) }\end{array}$ & 0.15 & 0.07 & 0.01 & 4.71 & $<.001 *$ \\
\hline
\end{tabular}

* Significant after a Bonferroni adjustment to the nominal alpha $(.05 / 10=.005){ }^{a}$ Through appearance reasons to tan. ${ }^{\mathrm{b}}$ Through appearance reasons not to tan 
Appendix B: (Continued)

Figure 1. Hypothesized Model

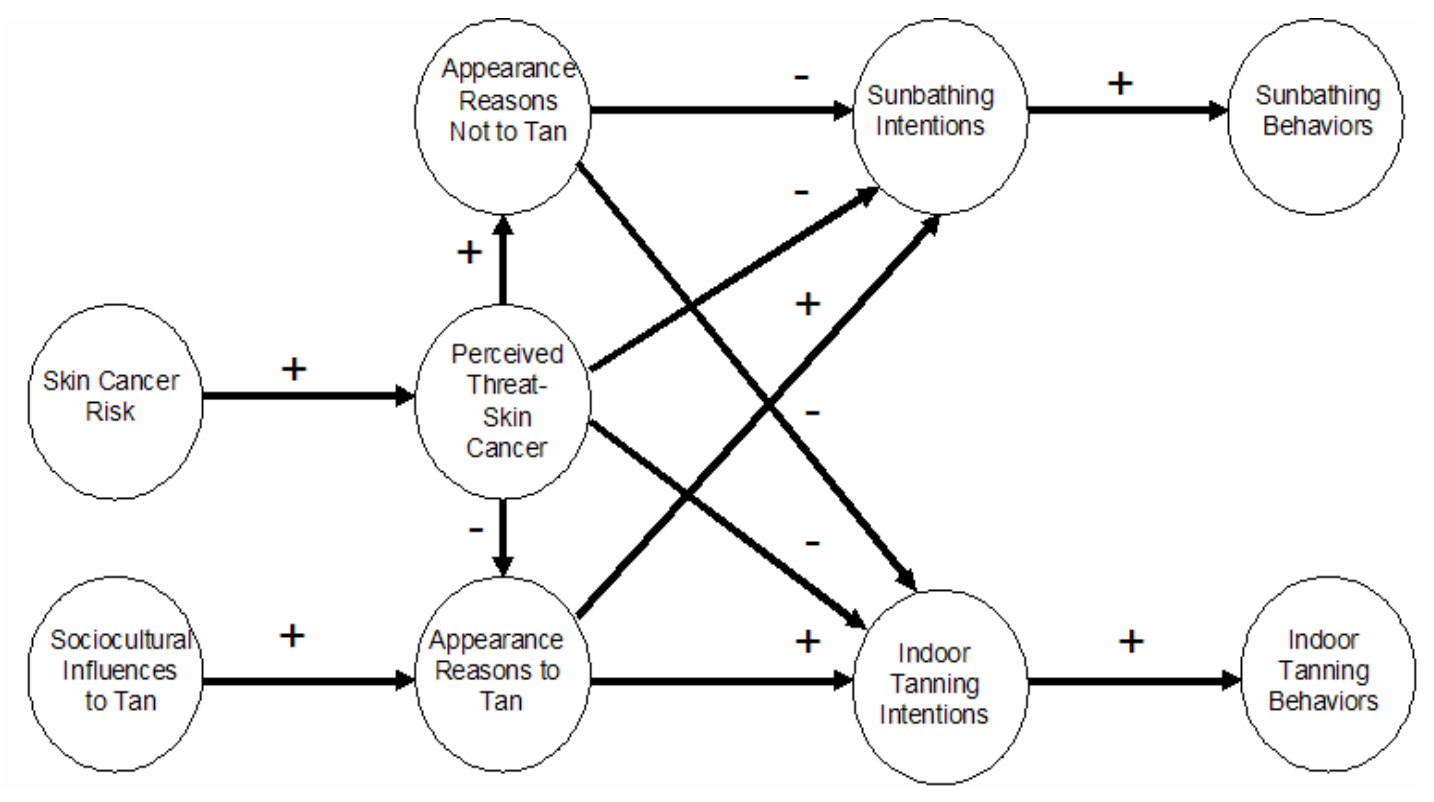


Appendix B: (Continued)

Figure 2. Alternative Models for the Role of Intentions and Behaviors

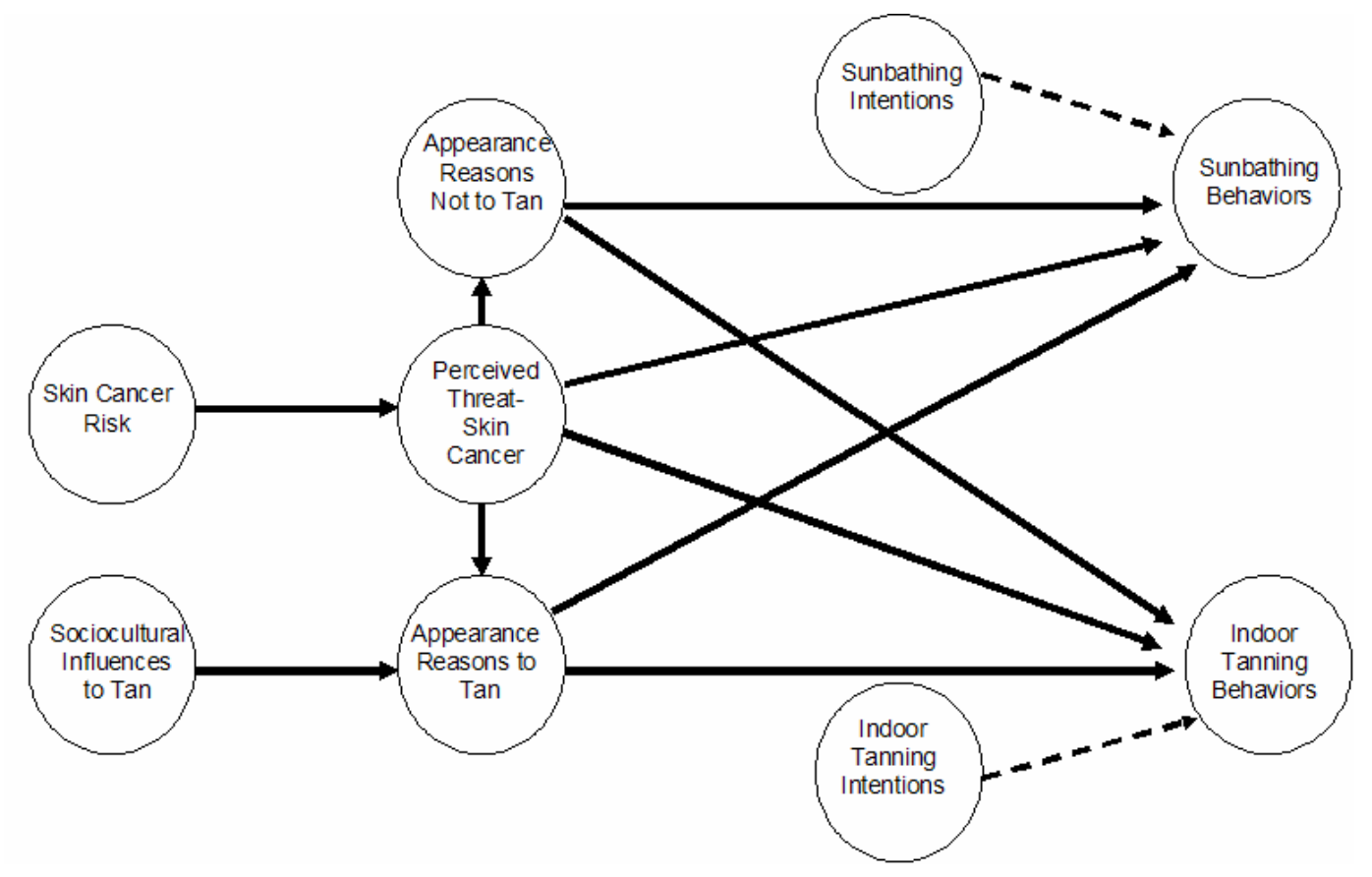


Appendix B: (Continued)

Figure 3. Alternative Model for the Role of Sociocultural Influence

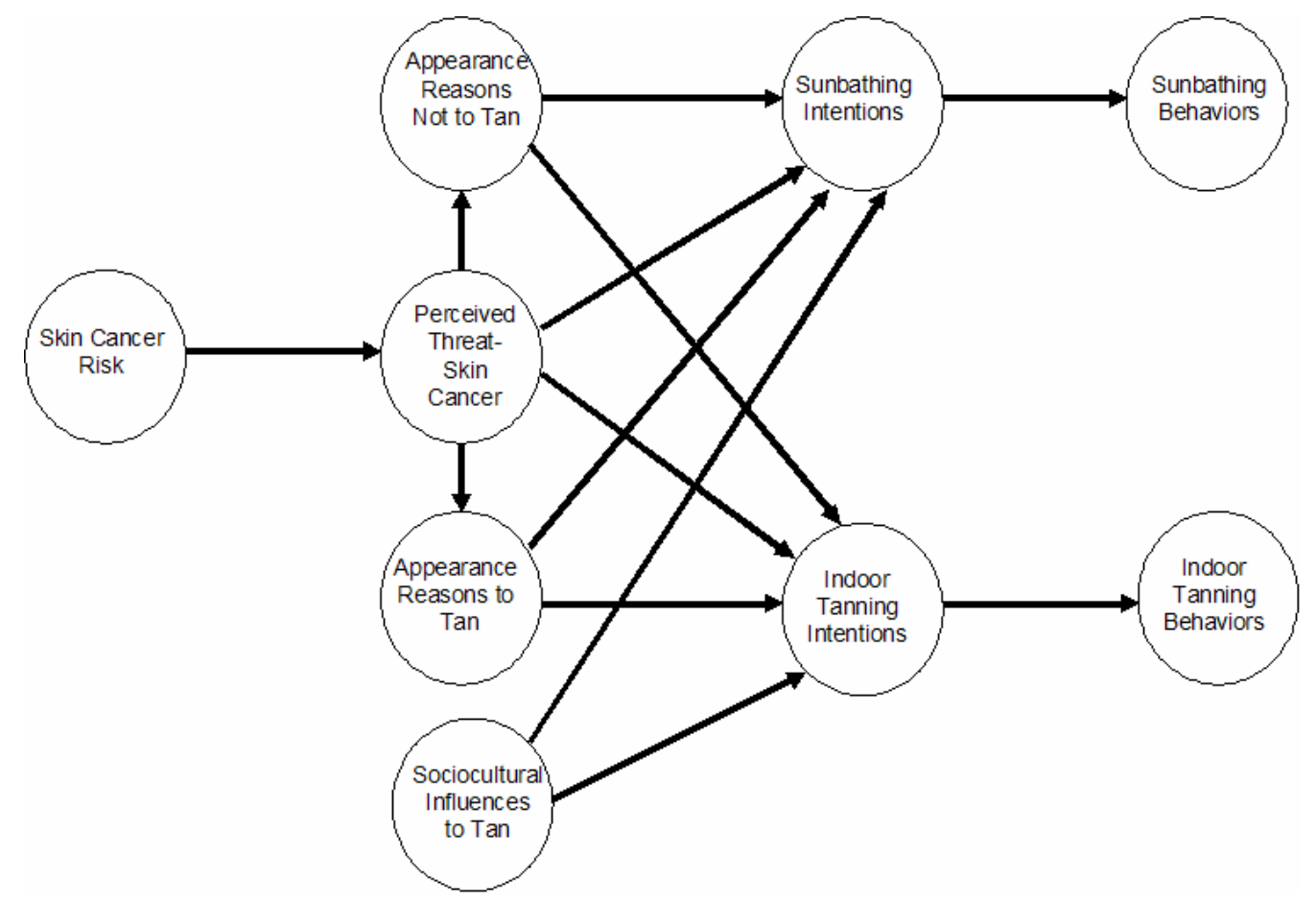


Appendix B: (Continued)

Figure 4. Alternative Models for the Role of Perceived Threat

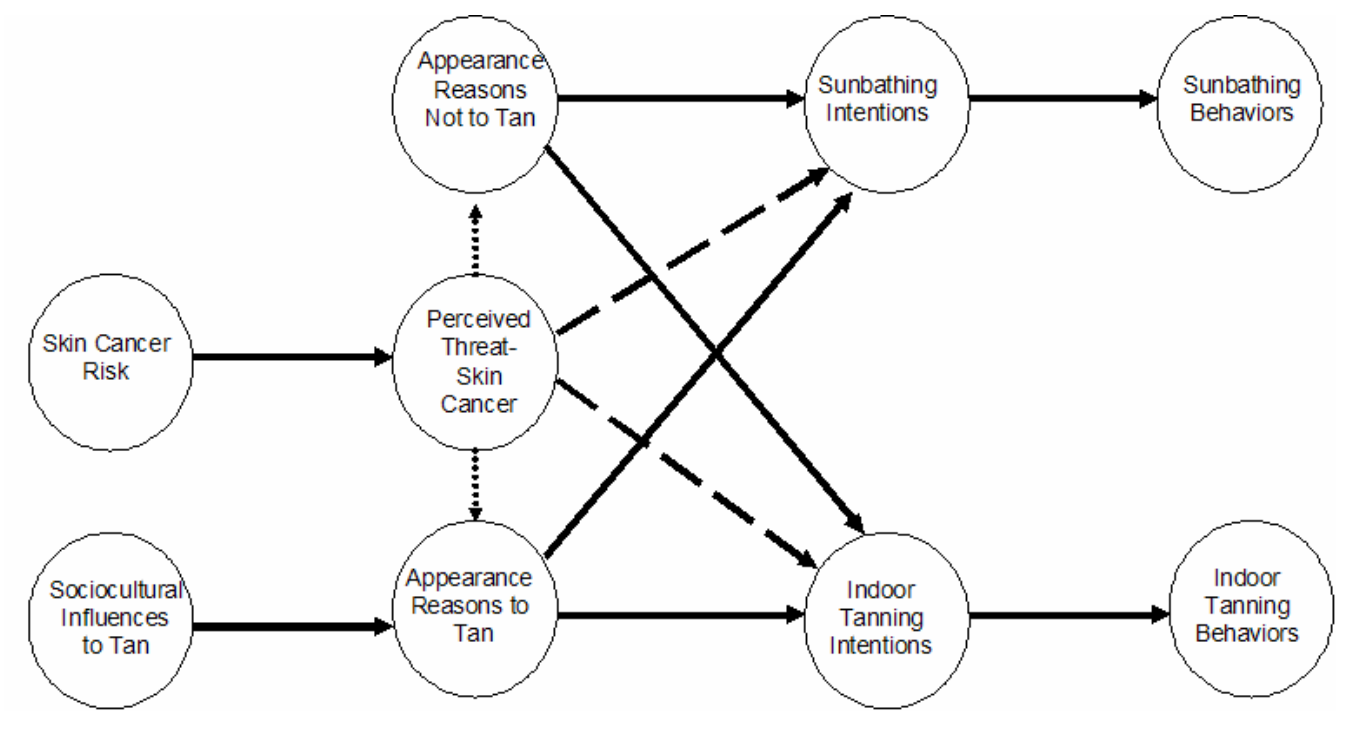


Appendix B: (Continued)

Figure 5. Alternative Model for the Role of Skin Cancer Risk

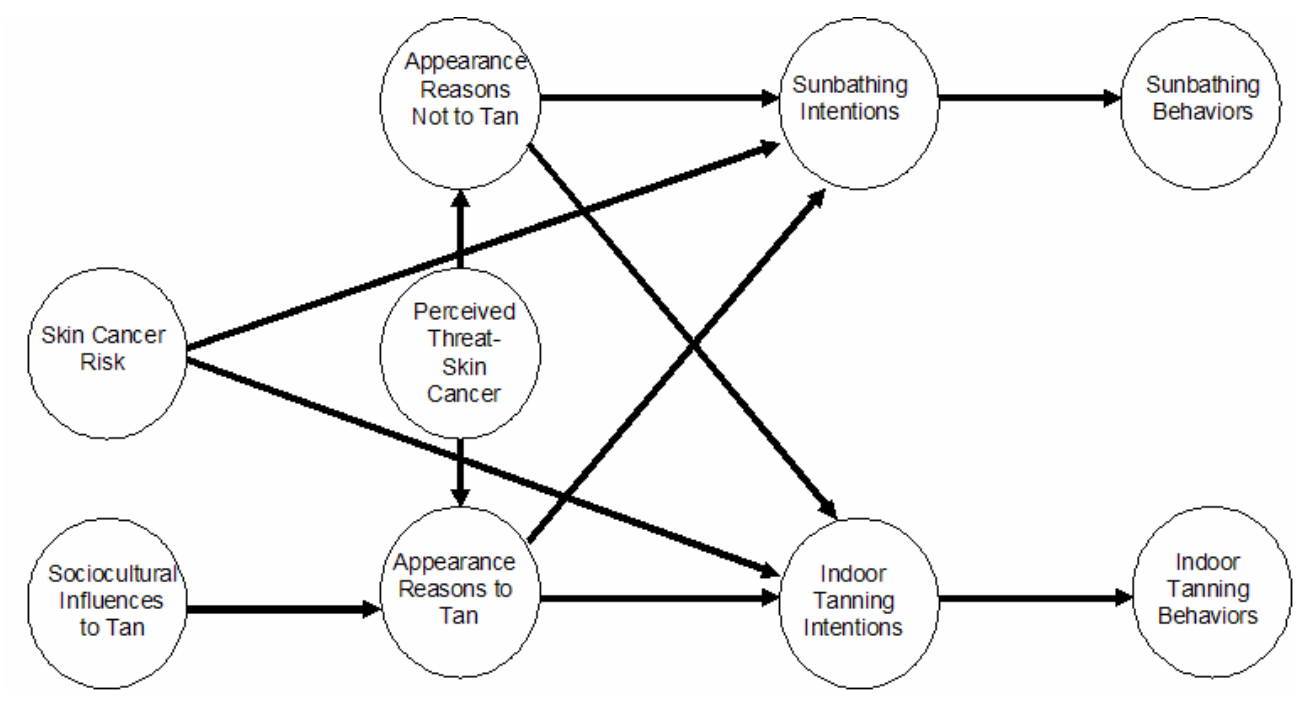


Appendix B: (Continued)

Figure 6. Standardized Path Coefficients for Final Model (without item deletion)

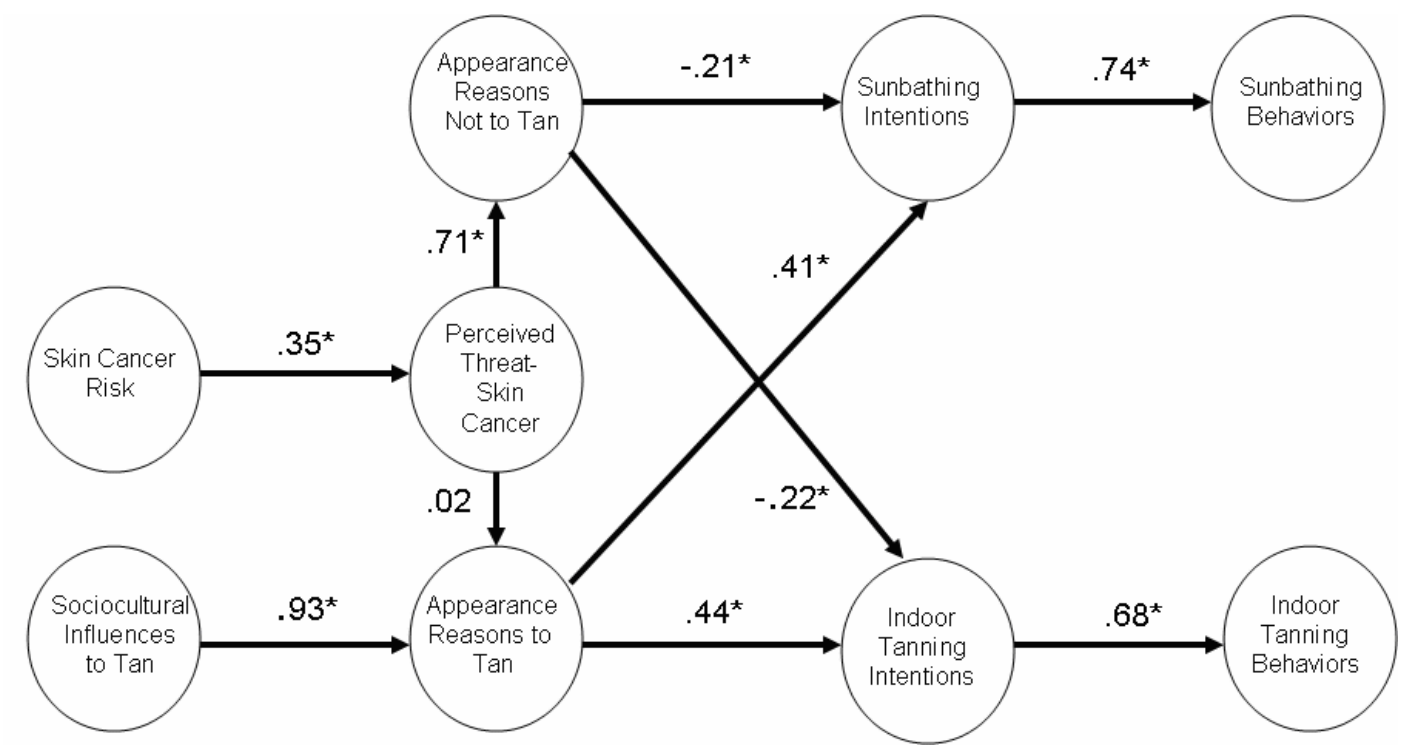

* Significant after a Bonferroni adjustment to the nominal alpha $(.05 / 10=.005)$ 
Appendix B: (Continued)

Figure 7. Standardized Path Coefficients for Final Model (with item deletion)

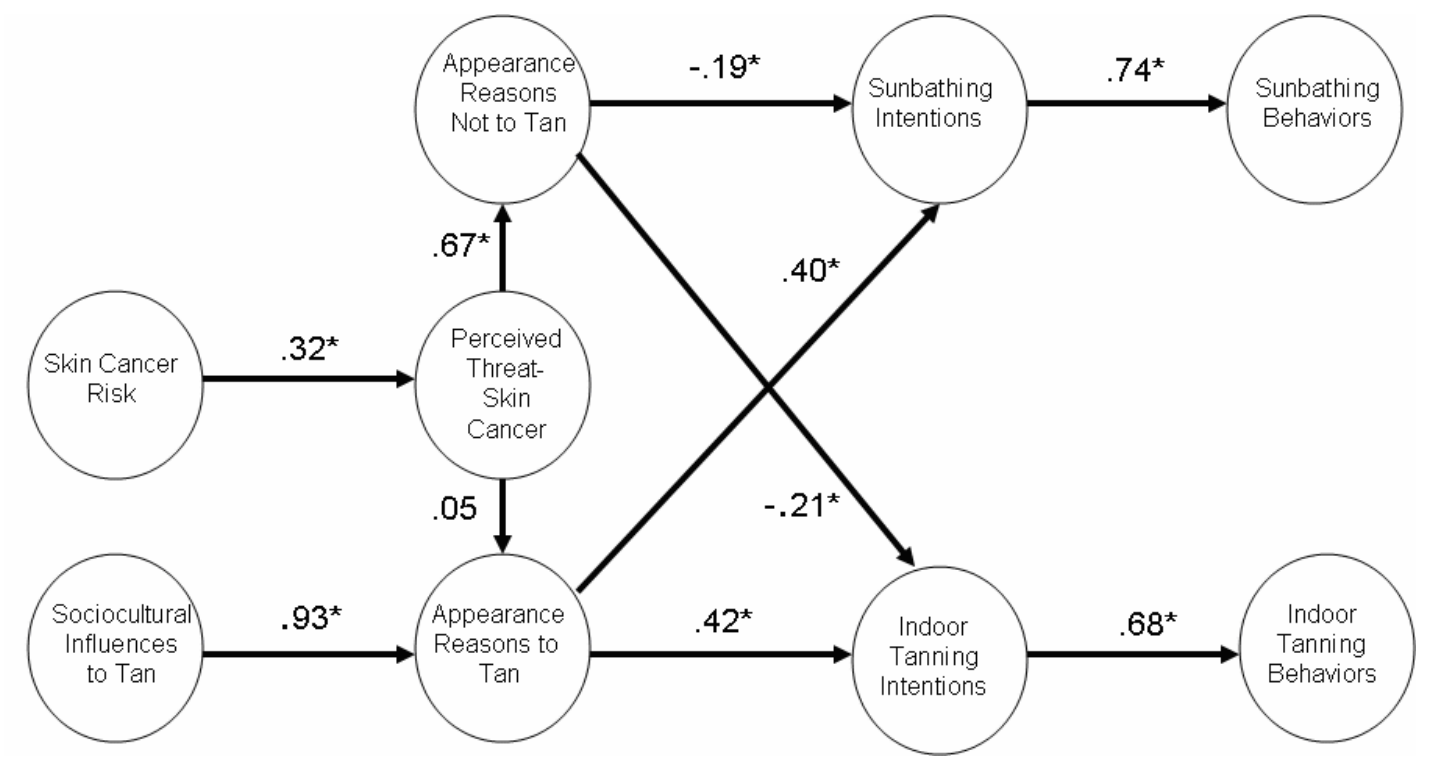

* Significant after a Bonferroni adjustment to the nominal alpha $(.05 / 10=.005)$ 
Appendix B: (Continued)

Figure 8. Standardized Path Coefficients for Final Model (with outlier deletion)

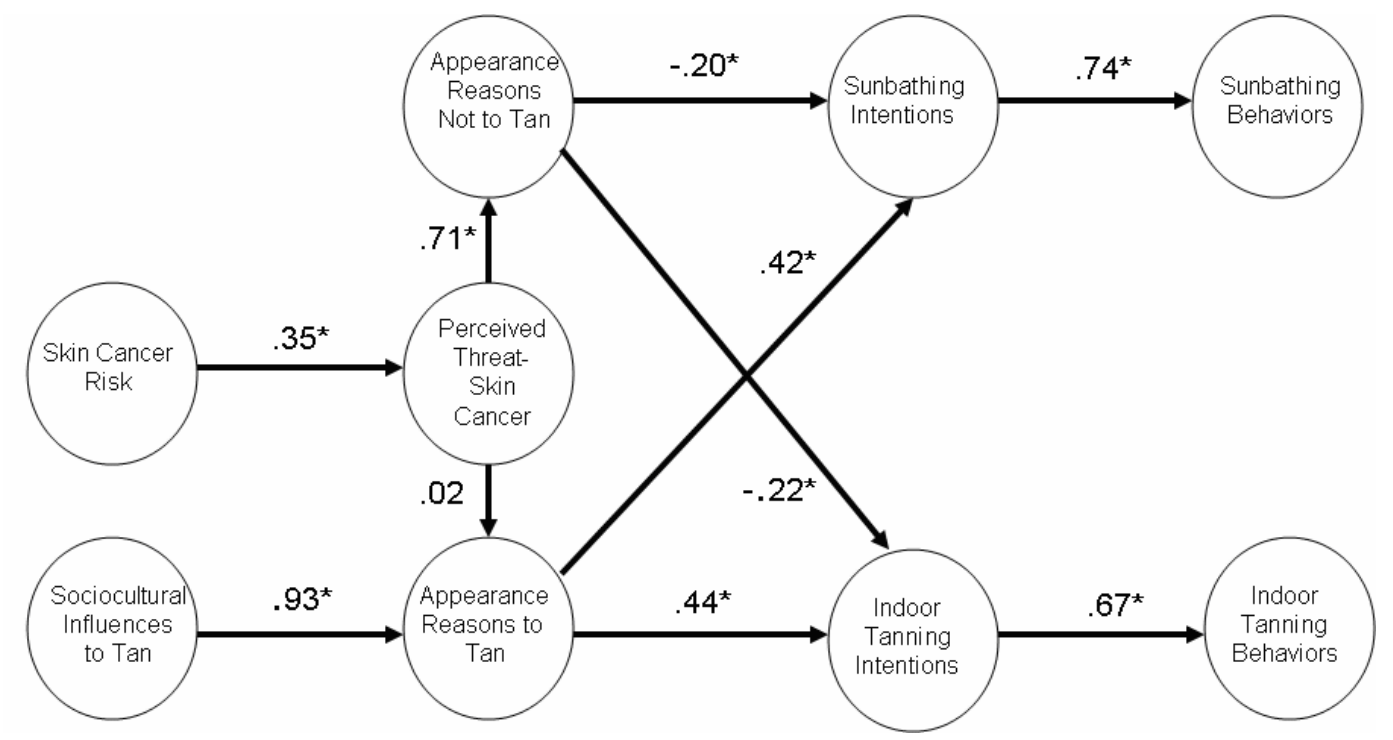

* Significant after a Bonferroni adjustment to the nominal alpha $(.05 / 10=.005)$ 


\begin{abstract}
About the Author
Guy Cafri received his B.A. in Psychology from Macalester College and M.A. in clinical psychology from the University of South Florida. He has published in the areas of: body dysmorphic disorder, steroid use, eating disorders, body image, and skin cancer prevention. In addition to these areas, he also has an interest in applied statistics.
\end{abstract}

